University of Louisville

ThinkIR: The University of Louisville's Institutional Repository

Electronic Theses and Dissertations

$5-2015$

\title{
The process of curating Trace of a Body : creating relationships and building experiences.
}

Bailey Marie Mazik 1990-

University of Louisville

Follow this and additional works at: https://ir.library.louisville.edu/etd

Part of the Art and Design Commons, Fine Arts Commons, and the History of Art, Architecture, and Archaeology Commons

\section{Recommended Citation}

Mazik, Bailey Marie 1990-, "The process of curating Trace of a Body : creating relationships and building experiences." (2015). Electronic Theses and Dissertations. Paper 2141.

https://doi.org/10.18297/etd/2141

This Master's Thesis is brought to you for free and open access by ThinkIR: The University of Louisville's Institutional Repository. It has been accepted for inclusion in Electronic Theses and Dissertations by an authorized administrator of ThinkIR: The University of Louisville's Institutional Repository. This title appears here courtesy of the author, who has retained all other copyrights. For more information, please contact thinkir@louisville.edu. 
THE PROCESS OF CURATING TRACE OF A BODY: CREATING RELATIONSHIPS AND BUILDING EXPERIENCES

By

Bailey Marie Mazik

B.A., Ohio State University, 2013

\begin{abstract}
A Thesis
Submitted to the Faculty of the

College of Arts and Sciences of the University of Louisville in Partial Fulfillment of the Requirements

for the Degree of

Master of Arts in

Art(c) and Art History Critical and Curatorial Studies
\end{abstract}

Hite Art Institute

Department of Fine Arts

University of Louisville

Louisville, KY

May 2015 

THE PROCESS OF CURATING TRACE OF A BODY: CREATING RELATIONSHIPS AND BUILDING EXPERIENCES:

\author{
By \\ Bailey Marie Mazik \\ B.A., Ohio State University, 2013
}

A Thesis Approved on

April 10, 2015

by the following Thesis Committee:

\begin{tabular}{c}
\hline $\begin{array}{c}\text { Thesis Advisor } \\
\text { John Begley }\end{array}$ \\
\hline Peter Morrin \\
\hline
\end{tabular}

Dr. Thomas Maloney 


\section{DEDICATION}

This thesis is dedicated to the two most important people in my life, my parents:

Timothy Mazik and Janet Mazik.

I will be forever grateful for your steadfast support, guidance, and love through every endeavor of my life. 


\section{ACKNOWLEDGMENTS}

Listening to life stories is one of the greatest joys I experience. Understanding the hearts of people, especially those I'm closest with, is what keeps me going.

To: Logan Mazik, Sara Santiago, Sarah Mutchler, Kaitlin Adegboye, Kelsey Tae Frady, Abigail Gordon, Hillary Sullivan, Stephanie Schmidt, and Hillary Dix - thank you for teaching me how to listen, mostly by your example of always listening to me. Thank you for being necessary, irreplaceable guidance and spice in my life.

To: Professor John P. Begley, Professor Peter Morrin, Dr. Mónica A. Walker, Professor Gabrielle Mayer and Dr. Thomas Maloney - thank you for your patience and cultivation. Thank you for being exemplary professionals and model educators. You each encourage and inspire me to be better and do more, for the right reasons.

To: Jessica Bennett Kincaid, Matthew Bradley, Mario Picciuto, Jake Ford, Abigail Gordon and Hillary Sullivan - thank you for your energy and helping hands! The installation and de-installation of the exhibition would not have happened as smoothly or enjoyably without you.

Finally, to Chris Radtke without whom this project would have been impossible. Thank you for making powerful art, allowing me to work with it, and mentoring me through this process.

Words are inadequate to express the depth of my gratitude. 


\title{
ABSTRACT \\ THE PROCESS OF CURATING TRACE OF A BODY: CREATING RELATIONSHIPS AND BUILDING EXPERIENCES
}

\author{
Bailey Marie Mazik
}

April 10, 2015

As the title suggests, this document details the course of curating an exhibition titled Trace of a Body and addresses larger themes of curating contemporary art. During spring semester 2015 the entire researching, planning, and implementation of the exhibition portion of this Master's thesis project took place. Trace of a Body was exhibited from March 12, 2015 - April 5, 2015 in Gallery X, Schneider Hall, Hite Art Institute, University of Louisville. The exhibition was a monographic show of work by Chris Radtke, a prominent contemporary artist working in Louisville, KY. It was a great opportunity to bring together the active Louisville art scene with the university. On a personal level, Radtke's art sparks important conversations about individual choices, impact from circumstances, and life in general.

The artist graciously loaned all the art for the exhibition and aided in the planning and implementation of installation works. The written component of this project addresses the curatorial process specific to this exhibition but also demonstrates the issues and rewards of curating contemporary art. 


\section{TABLE OF CONTENTS}

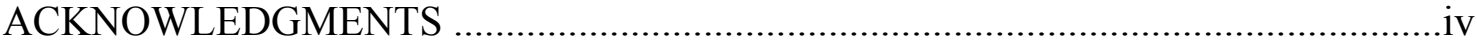

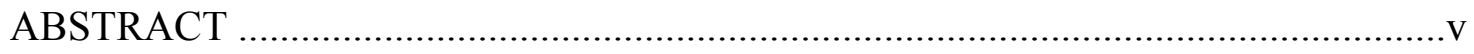

LIST OF FIGURES …….......................................................................................

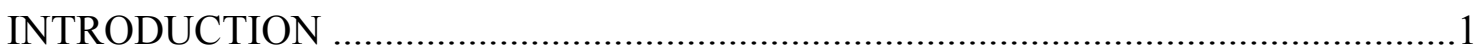

CURATING CONTEMPORARY ART ……………….........................................

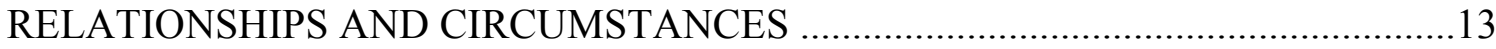

Early Life and Education ..............................................................................13

Adult Life and Louisville ...............................................................................14

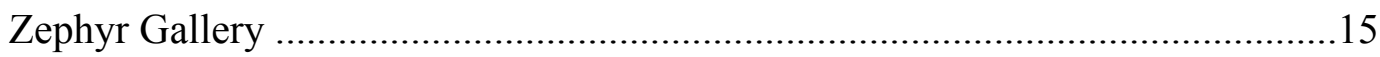

Present and Future ………………………………………………………....16

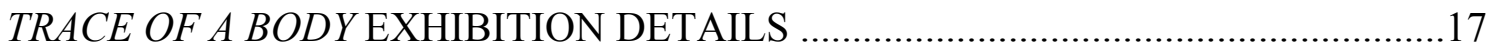

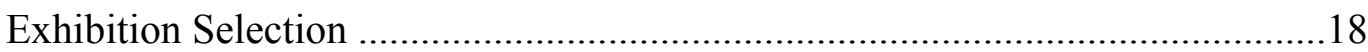

CHRIS RADTKE AND RECENT ART HISTORY ………………………………....24

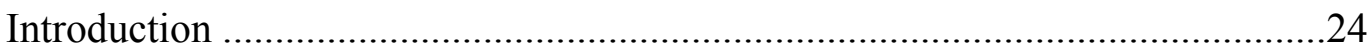

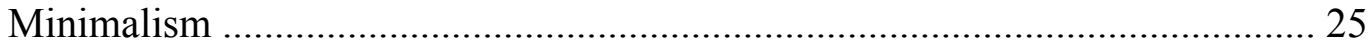

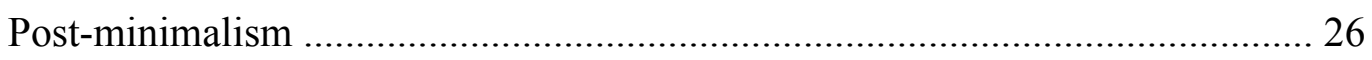

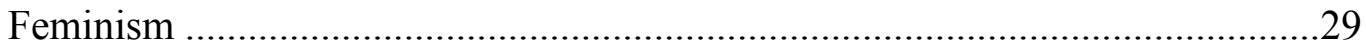

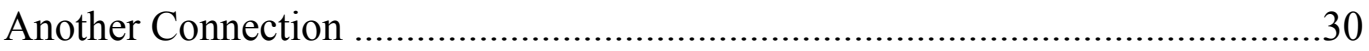

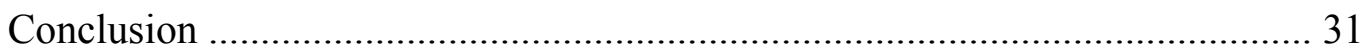

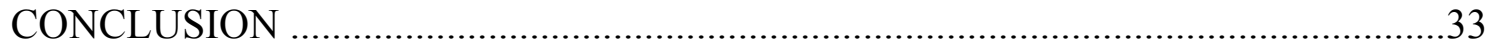




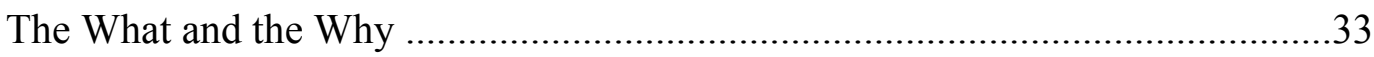

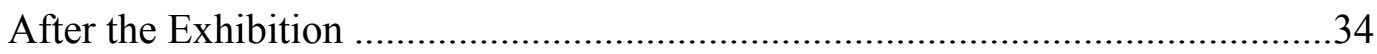

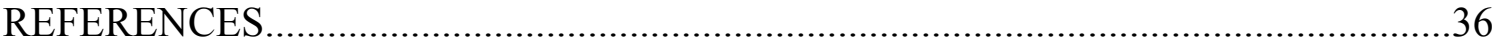

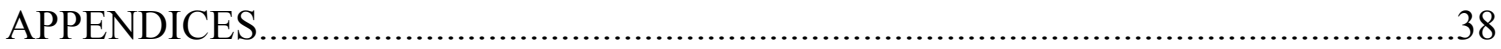

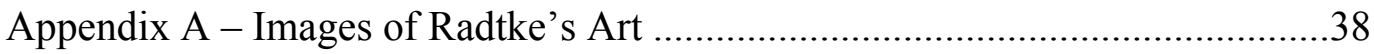

Appendix B - Trace of a Body Exhibition Installation Images .........................50

Appendix C - Images for A Brief History of Recent Art as Related to Chris

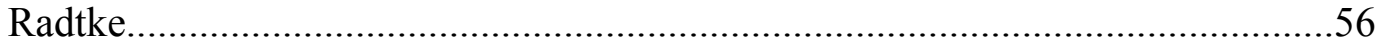

Appendix D - Didactic Material and Object Labels ........................................62

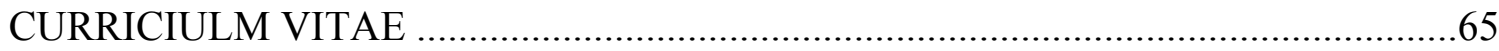




\section{LIST OF FIGURES}

IMAGE

PAGE

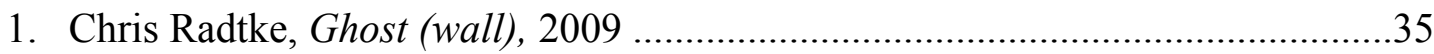

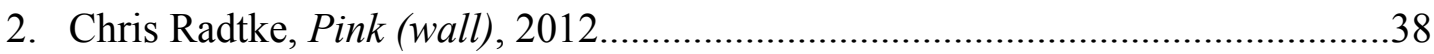

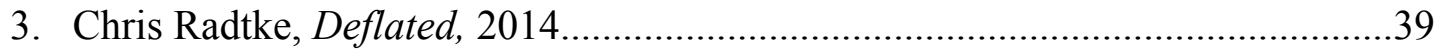

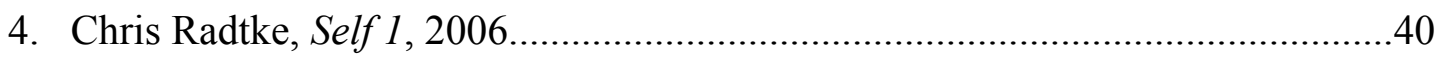

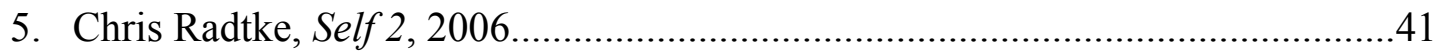

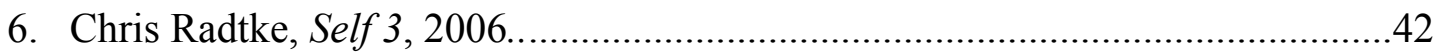

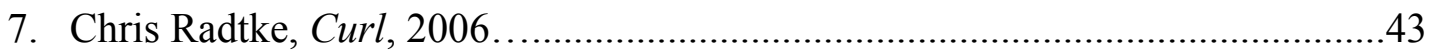

8. Chris Radtke, Crouch, 2006...........................................................................45

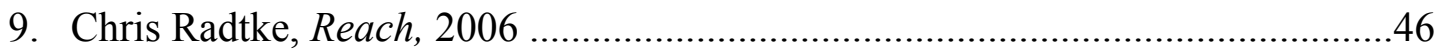

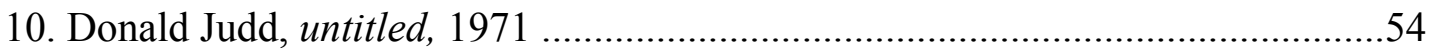

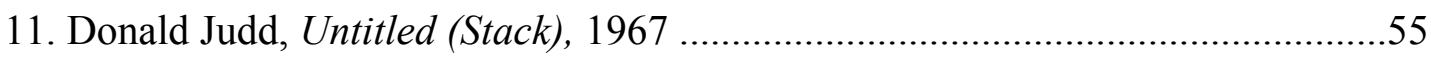

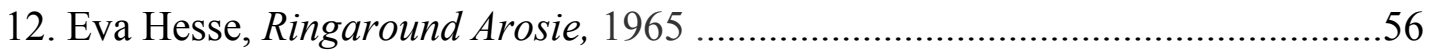

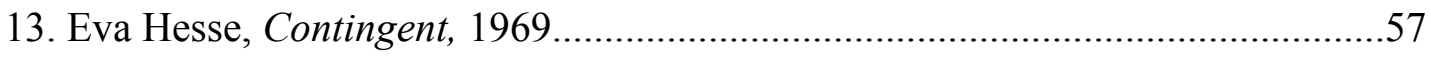

14. Judy Chicago, Dinner Party, 1979..............................................................58

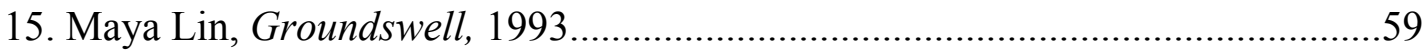




\section{INTRODUCTION}

For a year prior to this project I researched contemporary glass art with the intentions of pursuing it for my master's thesis. I was looking at how contemporary artists use glass as a medium and explore conversations of craft and fine art. Throughout the course of meeting with artists (both trained in glass and not) in Louisville I met Chris Radtke. A number of her works contain a glass component including broken tempered glass, flat transparent glass, and mirrored glass. After meeting Radtke and studying her

work, glass and otherwise, I was enticed to pursue her work alone for my master's thesis. 


\section{CURATING CONTEMPORARY ART}

\section{"I owe my first glimpse of art to a curator." - Terry Smith ${ }^{1}$}

Through the course of my studies along with my internship positions in museums, I have learned about and experienced the assortment of diverse demands on curators. I find it challenging to define and summarize the tasks and expectations of a curator. Each institution is unique and relies on its curator(s) to accomplish different goals. As Robert R. Archibald so frankly states, "No two museums are alike. Museums are endlessly, enchantingly diverse. Unlike scientists' quest for a 'theory of everything,' no such pursuit is desirable or possible for us in the museum field."2 Archibald speaks to the diversity and impossibility of uniformity through best practices that professional organizations attempt to establish, including conversation philosophies, deaccessioning policies, and even the credibility of museum professionals. ${ }^{3}$ As a student and young curatorial professional, this is a daunting but encouraging and exciting reality. There are better ways to operate and maneuver projects, such as curating exhibitions, but there is no

\footnotetext{
${ }^{1}$ Terry Smith, Thinking Contemporary Curating (New York: Independent Curators International, 2012), 24.

${ }^{2}$ Robert R. Archibald, "Community Choices, Museum Concerns," in Museum Philosophy for the Twenty-First Century, ed. Hugh H. Genoways (Lanham, MD: Altamira Press, 2006), 268.

${ }^{3}$ Ibid.
} 
best way, only room for experimentation met with discovery, criticism, and ultimately growth.

True to its unbridled nature, some of the challenges of museum and curatorial work have persisted through the decades. In 1975 Lawrence Alloway wrote about the challenges and facets of curatorial practice that he experienced, many of which are relevant today. He argues that a main tenant of curators dealing with modern art is staging temporary exhibitions, leaving the permanent collection of a museum on the wayside. ${ }^{1}$ This recognition abandons the traditional collect, preserve, interpret model of presenting art. Rather than conservation, collecting, and grooming a permanent collection, curators dealing with modern (and I will add: contemporary art) are met with the unique challenges of constant conception, planning, and execution of temporary exhibitions. Alloway details five unique pressures for these curators:

1. The desire to get along with the artist or artists.

2. The necessity to keep good relations with the artist's main dealer or dealers.

3. The necessity of maintaining collector contentment.

4. Taste expectations emanating from the trustees and director.

5. Taste expectations of other members of the curator's peer group. ${ }^{2}$

Here, curators wrestle with a bundle of opinions from a diverse cast of characters: creators, sellers, purchasers, decision-makers, and colleagues. He further asserts, "The curator is present either as the interpreter of a critical point of view or as agent for somebody else. As the latter, he can be viewed as either the artist's servant or the market's slave." It can be concluded that the ultimate utility of the curator is as a vehicle

\footnotetext{
${ }^{1}$ Lawrence Alloway, "The Great Curatorial Dim-Out," In Thinking about Exhibitions, ed. Reesa Greenberg, Bruce W. Ferguson, and Sandy Nairne. (New York: Routledge, 1996), 221.

2 Ibid., 224.

${ }^{3}$ Ibid., 225.
} 
for the interests of others. Curiously, he excludes the opinion and expectations of the public in this list of pressures.

Alloway argues that the voice of the curator is lost in the shuffle of pressure and expectations. He says, "The pleasure of belonging to the group, an elite, often outweigh the satisfactions of nonconformity." "It would be presumptuous to think this applies solely to curatorial practice. Even while there is no best practice for any one task, there are strong opinions to bend to.

The pressure to appeal to each of these pressures is present, even today. For my project, relations with the artist's dealer and collectors were irrelevant, since she is her own dealer (see Zephyr Gallery section) the constraints and the availability of work directly from the artist made it unnecessary. Rather, I felt the greatest pressure from the artist, appointed authorities in my academic program, and peers. Presenting compelling art that would potentially rouse professors and directors of academia in my institution was a primary concern of mine. During my studies I have been greatly challenged in the realms of philosophy and theory in art history and criticism and wanted to showcase art that struck me but also appealed to my developing criticism and understanding of critical theory and contemporary art. I found art that satisfied this criterion in the work of Chris Radtke, which led me to actively explore the desires and vision of the artist, who was extremely generous and considerate of my education and training. By nature I work to engage and excite each of these characters of authority but I also desired to inspire my curatorial peers and other students of fine art. Because I find the work of Radtke to be so compelling, through her engagement challenging conversations about loss, brokenness, and submission, I hoped to spark the curiosity of my collegiate community.

${ }^{4}$ Alloway, "The Great Curatorial Dim-Out," 224. 
While Louisville has a variety of opportunities to interact with original, contemporary art, much of what is studied in academic courses is through reproductions. I was eager to use my project as a platform for sharing important contemporary art, in this case some installation and site-specific work, that is nearly impossible to fully grasp through reproduced images. Radtke is not yet in art history books and her work is singular but touches on very important broader contemporary themes, such as the physical self, and identity. It also mirrors innovations in the work of artists who are discussed in art history courses, such as Eva Hesse and Donald Judd. For all of these reasons my curatorial decisions evolved from ideas and desires to better understand how these characters and relationships operate.

Seemingly ordinary components of the gallery set up and presentation of the exhibition as a whole, including the placement of lights in the track and inclusion of a bench for visitors to rest and contemplate, were thoroughly considered and discussed through the course of this project. As a curator, unlike Alloway's lack of consideration of audiences, I intend to make visitors feel welcome and invited to rest while they study the art before them. From the initial stages of curating Trace of a Body I wanted to include a bench in the gallery. Through the course of installing, after I positioned the bench where I found most appropriate, Radtke raised concerns about its inclusion. She was worried it would confuse visitors. Due to the geometric value of the sculpture in the exhibition and low profile of one of the works, she was concerned that the bench would be mistaken for one of her works. Thus, I decided to exclude the bench. Facilitating a place for contemplation and conversation is the foundation on which I operate and I chose to negotiate elements of the exhibition, mainly the bench, away from my core values due to 
Radtke's uncompromised dedication to her work. Ultimately, I chose to respect the concern of the artist and her work over those who would participate as viewers.

Sophia Krzys Acord, a sociologist, views the practice of curating contemporary art with a different, perhaps uplifting, lens. She argues, "The crux of curatorial practice in contemporary art is the construction of artistic meaning through the exhibition." For her, contemporary art relies on public exhibition for forming the meaning of the work. "In contrast to the taxonomical or art historical approach to exhibiting traditional art, the exhibition process in modern and contemporary art is integral to the meaning of the art work." ${ }^{6}$ For example, installation art and site-specific works would be unavailable if not displayed in the context for which they were conceived. In this sense, the curator is the tastemaker and authority, which is an indispensable role in the pulse of contemporary art, rather than the peacekeeper and appeaser between casts of characters.

Working with Radtke and learning about her process has proven, to me, that the exhibition of her work is crucial to its understanding. Light and temperature along with the architecture of a space all play a role in her art. The tailoring of works to a space and the unique moments that occur during installation are just as important to her and her art as the hours, days, and months in the studio. Acord speaks to this phenomenon also: "The artistic value of an art work resides not in its material properties, but in the individuals, institutions, and processes that mediate between artist and spectator."7 While this bold statement is not completely accurate ${ }^{8}$, in the case of Trace of a Body the material

\footnotetext{
${ }^{5}$ Sophia Krzys Acord, "Beyond the Head: The Practical Work of Curating Contemporary Art," Qualitative Sociology 33, 4 (2010): 447, accessed March 25, 2015, doi: 10.1007/s11133-010-9164-y.

${ }^{6}$ Ibid., 449.

${ }^{7}$ Ibid.
} 
properties and mediations between the conception and exhibiting are equally important. Each step of Radtke's artistic process, my decision to exhibit her work, and the collaborate effort to realize the exhibition plays a critical role in what Acord calls the artistic value of artwork. ${ }^{9}$

Acord detects the unsystematic practice of curating temporary exhibitions, as Alloway outlined, when she addresses the reality of unplanned circumstances. "Although curators engage in lengthy, detailed discussions with artists about the medium and nature of the work, curators cannot know the final outcome in advance, nor prepare for what they will experience in their first encounter with the finished work. ${ }^{, 10}$ Married with the inherent beauty of site-specific art is an air of uncertainty that must be accounted for. Months of meticulous planning and consideration can be poured into a project but as studying original art is always more revealing than its reproductions, so is handling the actual art in the actual space apart from preliminary measurements and calculations. This difficulty of installing was encountered in the calculating and recalculating of the work Ghost (wall) 96 and Pink (wall) 8. It was not until Radtke and her installation assistant inspected the walls on which the works were to be hung that a plan was finalized. The original plan Radtke had sketched out was ultimately revised for the actual installation. Similarly, the decision to exclude one of the works came only when the show was mostly placed and physically interacted with.

\footnotetext{
${ }^{8}$ This claim is inaccurate because it assumes there is no value in the material properties. Acord places total importance on people, in this case curators, but neglects the fact that curators act as mediator between artist and spectator because they find artistic value in the physical work. The value of art does increase with each exhibition but mediation is not the sole proprietor of value, it is rather a contributor.

${ }^{9}$ Ibid.

${ }^{10}$ Ibid., 453.
} 
Overall, the exhibition of modern and contemporary art is a place of learning and experimentation. For artists, exhibiting in a public place has the potential to dictate the limits of art they create. Conversely, the requirements of a work of art dictate whether or not a curator can facilitate an exhibition. Some works may be too large or demanding for a particular institution to manage on a variety of levels. The mission and message of works may not be fully portrayed through the installation of work through the emergence of unforeseen complications, as mentioned earlier by Acord. ${ }^{11}$ Regardless, installations and exhibitions should be a learning environment for all viewers and participants. Acord asserts, "Seen as a knowledge-producing society, rather than simply a social 'reproducing' society, the study of artworks as they are mobilized by other mediators in their worlds allows sociology to understand how aesthetic objects (as explicit culture) play an important role as arbiters of social relations, meaning and action." ${ }^{\prime 2}$ In this sense, curators are students and educators as they are constantly granting importance to ideas, objects, and people but are also constantly being challenged and learning throughout the process.

Important, defining characteristics of curating contemporary art are the themes of time and space. As illustrated by the work of Radtke and Trace of a Body, contemporary art and exhibitions spark important conversation, about submission, brokenness, reflection, and depletion. Terry Smith, art historian and critic, argues that contemporary art must engage with place making, world picturing, and connectivity in order to be considered "contemporary". ${ }^{13}$ Radtke's work appropriately satisfies this definition as it creates new and unusual environments that also call personal space, response to

${ }^{11}$ Ibid., 454.
${ }^{12}$ Ibid., 460.
${ }^{13}$ Smith, Thinking Contemporary Curating, 28. 
nature/environments over time, and universality into question. When working to exhibit contemporary art Smith asks, "Can we say that the purpose of curating today is something like this: to exhibit (in a broad sense of show, offer, enable the experience of) contemporary presence and the currency that is contemporaneity as these are manifest in art present, past, and multitemporal, even atemporal?"14 Here, Smith grants agency and responsibility to the contemporary exhibition, the curatorial field and its viewers.

The constant evolving nature of curatorial work is further proved by the vernacular used to talk about it. As discussed by Smith a number of scholars in the field of art history and curating, including Robert Storr and Walter Hopps, use metaphors in an attempt to succinctly explain the process of curating. These metaphors include conducting an orchestra, directing a film, and editing a body of literature. ${ }^{15}$ While these are all appropriate comparisons, as the presence of work created by designated artists (musicians, actors, and writers) meets the requirements of an appointed authority, Storr and Hopps suggest that curating is banal. ${ }^{16}$ By comparing it a variety of endeavors it undermines exhibition curating's unique challenges. This leaves me wondering why curating and installing a temporary exhibition is not an analogy for directing a film. It prompts an inquiry into the power of language and forms. And the curator must recognize these relationships as this as the exhibition evolves.

One task of any curator is always uncompromising attention to detail, including the treatment of text and didactic materials. There may be a general consensus about the construction of object labels and text panels but there is not a single best practice; however, there are few rules. Smith speaks to the fluctuating theory behind text

\footnotetext{
14 Ibid.

${ }^{15}$ Ibid., 37-38.

${ }^{16}$ Ibid., 38.
} 
interacting with works in the exhibition. ${ }^{17}$ Some individuals and institutions include minimal text, perhaps just the title of the exhibition along with simple object labels. For Trace of a Body I intended to have a balance of curatorial interpretation and allowance for personal, unguided experience. Thus, I included only three extended labels about works in addition to an opening statement about the exhibition and object labels. I worked to draw attention to themes and share personal narratives of Radtke, since her work is autobiographical, in a manner that would be universal and engaging with visitors.

When dealing with contemporary art, especially installation work, the roles of artist and curator become intertwined. First, the curator makes the decision to exhibit an installation work but, in the case of Trace of a Body, the artist shared this responsibility in curating the work by helping to determine the exact size and placement. Rather than dictating the size and placement of the work, I instructed and trusted Radtke to formulate a plan to her liking and followed her lead to realize the final product. Another example of ambiguous responsibilities and intermingled artistic process arose when I was charged with breaking glass for $\mathrm{Curl}$. For this particular work Radtke installed the first section of broken glass to her liking and not only instructed me to complete the second section of broken glass, but trusted me to finish the product.

As I was refining Curl the best I could to the specifications she left me, the artistic process was cast in a different light. Part of the reason I selected this work was her process: how she initially came to using glass and breaking it, what it meant to her originally and how that meaning has transitioned and grown through time and exhibitions. What did it mean now that I was breaking a new batch of glass? The end product could never be indicative of the process or single me, the curator, out from

${ }^{17}$ Ibid., 45-46. 
Radtke, the artist. But the extended label I wrote for this work, which was displayed for the public to read, said otherwise as it placed importance on Radtke's process. In "The Curator's Moment" Michael Benson touches on these blurred lines between curator and artist. While this article discusses contemporary international exhibition (biennials, international art fairs, etc.), I find Brenson's arguments supportive of exhibiting contemporary art in general. He argues:

"The increasing centrality of the curator has also been reinforced by the emergence of installation as the standard form in which contemporary artists around the world are working. Installations involve selecting and arranging in a space often shared by visitors. They may also involve writing and educating. Installations were designed, in part, to contextualize and therefore empower themselves by inscribing within them an awareness and even the look of a gallery or museum. By so doing, however, they implicitly acknowledge the curator's inescapable authority. Blurring the line between artist and curator builds into the experience of art a heightened awareness of the curator's reality."

The seed of creativity and initiation will continue to be credited to the artist, without a doubt. But it is the curator who champions and maintains the momentum to fully realize the work.

Flexibility, innovation, agility, enthusiasm, criticism, open-mindedness, and devotion are a few characteristics among many that the contemporary curator must exercise. Whether working independently or within an institution, curators working with contemporary art face many of the same challenges. Roberta Smith observes, "Curators have about the most complicated and daunting job in the art world; they are pulled apart by pressures to raise money, write, hunt out hot new artists and oversee acquisitions, while organizing shows that attract the public." ${ }^{, 19}$ Curators are relied upon to be both

\footnotetext{
${ }^{18}$ Michael Brenson, "The Curators Moment," Art Journal 57:4 (Winter 1998), 18.

${ }^{19}$ Roberta Smith, "An Alien Sighting on Planet Pittsburgh," New York Times, May 9 2008, accessed September 18, 2013. http://www.nytimes.com/2008/05/09/arts/design/09carn.html?pagewanted=print
} 
dependable and challenging. They are expected to be reliable but innovative, to be a rock and a wave. As blurred as tasks are and as indefinable the language used within and about it is, curators find a way to accomplish their goals and fulfill multiple expectations, including providing engagement with new ideas, forms, and materials, because they are the pulse of contemporary art. 


\section{RELATIONSHIPS AND CIRCUMSTANCES}

\section{Early Life and Education}

Chris Radtke was born in 1946 and raised in Detroit, Michigan. Her father was a physician and her mother was one of few women who worked for an architectural and engineering firm in Detroit. Radtke is the oldest of four children; she has two sisters and a brother. Her youngest sister is a dancer and choreographer. Her brother is a medical doctor, like their father and her other sister is a registered nurse. She has been surrounded by medical and artistic influences her entire life and thus has remained curious, informed, and comfortable in both realms.

Throughout her adult life, starting with her undergraduate studies, Radtke has relocated many times. The first two years of her undergraduate studies were at the University of Wisconsin-Madison where she majored in English. She transferred to Michigan State University for the latter two years of her undergraduate studies and also changed her major to studio and painting, finishing her Bachelor of Fine Arts degree in painting. 


\section{Adult Life and Louisville}

After completing her undergraduate studies, Radtke began her professional career as a teacher in the public school system of Detroit. Over the years she worked with students of a variety of grades, ages, and needs, including those requiring a special education curriculum. Reflecting on this period of life, she describes it as an extremely creative and rewarding time, but also mentally and emotionally draining.

During her adult life Radtke lived in Michigan, Iowa, Florida, North Carolina, and finally Kentucky. The moves were necessary for her husband's medical education and career, and Radtke took advantage of the relocations and the variety of artistic educational opportunities in each of these places. She remembers her artistic training as being sporadic while she and Norm Radtke moved from place to place, and even wild, but exciting. It was the 1970s, and she and her husband did not have many positions, which allowed for a simple, uncluttered life. ${ }^{20}$ And along the way two children, Erica and Tyson, as well as a dog, transformed the family of two into a family of five. This family of five made their last move from North Carolina to Louisville, Kentucky in 1980.

Throughout my visits with Radtke I became familiar with her entire oeuvre, beginning with her undergraduate work, but she indicates the 1980 s as being a particularly momentous period in her art and direction. During the 1980s Radtke married her artistic practice with research about genetics and its position in society. The economy, law enforcement, criminal justice, and public policy were all developing with the advances of genetic research and utilization. Issues of mutations, identity, offspring, and

\footnotetext{
${ }^{20}$ Her emphasis on remembering and relating a time when their life was 'uncluttered' implies to me Radtke's desire to maintain simplicity when possible. I understand it as controlling the aspects of life that one can, when so much is out of one's control. I see these important themes of focusing on and appreciating the calm and simple throughout her art, something that attracts me a great deal.
} 
individual/personal choices were also intermingling with scientific research and advances. In this sense, the traditional division and balance of science and art emerged, joined together, in Radtke's art. In the decades since, Radtke has dedicated herself and her work to exploring the complications of genetics, personal space, and unforeseen circumstances. The works included in Trace of a Body are from a later period in Radtke's career and did not address the theme of genetics, but rather serve as a propellant for studying and utilizing her body and personal space.

\section{Zephyr Gallery}

Aside from her personal artistic practice Radtke co-founded Zephyr Gallery, a cooperative artistic effort. When she first moved to Louisville in 1980, Radtke remembers the Louisville Visual Art Association being the only "game" in town, along with two commercial galleries. She and a group of fellow artists saw the need for a different artistic platform. In 1987 this group of artists purchased a space where their vision could be realized; this was the official founding of Zephyr Gallery. The gallery has relocated a total of five times, to different neighborhoods in downtown Louisville. The co-operative intentionally moved to areas that were not high traffic, partly due to lower rent, but each location they chose soon developed into thriving areas of commerce which resulted in higher rent. They have been at their latest location, 610 East Market Street Louisville, Kentucky, since 1997. Interestingly, this section of East Market Street has since developed into a prosperous, community full of innovative businesses and restaurants, known today as "NuLu."

It is important for Radtke to note that Zephyr Gallery was always a for-profit organization. She asserts that they did not want to be told what to do; they simply wanted 
to make enough money, as a group, to pay the rent. ${ }^{21}$ In this statement Radtke neglects the reality of for-profit organizations reporting to a governing body, often a board of directors, trustees, or shareholders. Rather, this attempted distinction between non-profit and for-profit organizations demonstrates the necessity of autonomy for her. Independence and singular inquiry are important, persistent themes her art as well as her life.

\section{Present and Future}

Along with being a vital figure in Zephyr initiatives, Radtke continues to create art. Presently, she is metaphorically and literally expanding her idea of personal space. Her sculpture, which until now has generally addressed her unique, personal space, is being challenged as she works to create ambiance through site-specific installations. She continues to employ series of units consisting of the dimensions of her body in different positions as the module for the installation works. She intends to continue creating environments and experiences.

${ }^{21}$ Chris Radtke, interview with the author, February 9, 2015. 


\section{TRACE OF A BODY - EXHIBITION DETAILS}

"Making art for us is, in principle, the way in which we create relationships in the world and through which we build life experiences. Being an artist is an expression of the soul that takes form in work and in daily life. We firmly believe that the responsibility of the artist is to act with awareness in order to produce and inspire responsible changes in oneself, in personal relationships, and in society." - László Moholy-Nagy ${ }^{\text {. }}$

The goal of this exhibition was to show Radtke's diversity in her practice while working with one topic: her personal space. Diversity is proven through her range of material: nylon mesh, wood, broken glass, mirrors, and plastic. The diversity in material used pushes her singular inquiry. It begs the viewer to find commonality among the works and while doing so demonstrates how the trace of her body is imprinted in a variety of scenarios. In the exhibition these scenarios occurred on the gallery floor, walls, and in the environment. These scenarios in the gallery could be translated into metaphorical or hypothetical life experiences, for example loss. The works explore questions of submission, breaking, deflecting of self, and depletion by intentional and unintentional infliction. Intentionally, Radtke and her choice of materials and unintentionally by the conditions of their installation, including gravity, air temperature, and light, Radtke sets up these challenges to viewers. These are daunting behaviors to deal with in interpersonal, as well as intrapersonal, capacities but are inevitable and confronting these happenings was the anchoring goal of this exhibition.

\footnotetext{
${ }^{1}$ The twentieth century artist was speaking directly about artistic practice but these values of forging meaningful relationships, building life experiences, and prompting positive change are, or should be, just as significant to curators.
} 


\section{Exhibition Selection}

For Trace of a Body I selected five works of art: Ghost (wall), Pink (wall), Deflated, Self 3, and Curl. These works were all created between 2006-2014 and relate to each other in dimension, as the specific templates are reused from one work to another. These works showcase Radtke's use of diverse materials and how she capitalizes on subtle differences in how the materials respond to their circumstances.

Ghost (wall) (2010) (fig. 1) is a site-flexible work of art that is adaptable to the dimensions of any wall it is to be installed on. In the case of Trace of a Body, Radtke and I decided that it would be installed on the longest, west wall when entering Gallery X. This wall is approximately 40 feet in length and 13 feet in height. The work consists of a series of white boxes, made from nylon mesh and completely enclosed. The dimensions of these individual boxes are the volumetric size of Radtke's body as she crouches into a small, compact unit. Together the assembly of these boxes into a full, wall-sized grid creates a curious ambience as the boxes play with light and submit to gravity.

This work has been exhibited in several venues including Zephyr Gallery in Louisville and Cedarhurst Center for the Arts. At each location the number of mesh boxes varies and emphasizes Radtke's overall intention: her body's dimensions remain consistent but the environment causes it to evolve and respond organically to different factors. Boxes droop, sag, and implode with time as gravity pulls on them and temperature increases their malleability.

Pink (wall) (2010) (fig. 2) is very similar to Ghost (wall) in that it is also siteflexible and uses the same dimensions of Radtke's crouched body. The same white nylon mesh is also used on all but one side. The one side of the mesh boxes that is not white is a 
vibrant pink color, as its namesake states. The boxes again respond to gravity and light but have a more assertive presence than Ghost (wall) does.

Radtke shared with me criticism of her work and her encounters with sexism and ageism. She has gotten significant negative feedback regarding this particular work as it is interpreted to be reminiscent of vaginal imagery. ${ }^{22}$ It is reminiscent of vaginal imagery due to the way the work is installed. Radtke pairs two lines of boxes and matches two pink sides with each other. For this exhibition the work is a grid of two boxes wide, four boxes tall, creating pink presences. Between the materiality of the nylon mesh and its pull from gravity, organic folds and crevices emerge. While perhaps criticized, she continues to adamantly install and present this work in this manner.

The physical submission of the mesh boxes to gravity complicates the prompted feminist discourse. Here the intention behind the display is unapologetic. It is not to satisfy the historically repressive male gaze or scrutiny, but rather for empowerment. However, the materials and its predetermined installation leave no option but for the boxes to submit to gravity, light, and shadow play. It is both a celebration of and proclamation about feminism in society.

I decided to include this work because I do not want to shy away from these potentially controversial conversations. I find it fascinating how similar Ghost (wall) and Pink (wall) are physically and conceptually and yet how varied the reactions are. In a way, the inclusion of this work is an experiment. I am curious as to how viewers in the academic setting will respond and if it differs from other venues and whether its content is more accessible to an academic audience.

${ }^{22}$ Chris Radtke, interview with the author, January 29, 2015. 
Deflated (2014) is work consisting of two pairs of rectangular containers (fig. 3).

The pairs are installed on a wall and made of tinted neon plastic: one pair is orange and one pair is pink. The vibrant colors and solid plastic materiality are a break from the subtle mesh used in other works and raise different questions of transparency as they interact with light. Radtke has observed that while her mesh works respond to gravity in a downward sagging motion, Deflated responds in a vertical flattening motion. The rectangles seem to hug and press against the wall on which they are mounted. In the vein of showing Radtke's diversity in material, I decided to include only the orange pair in this exhibition since the color pink was present in Pink (wall). This exhibition is the first for this work; the only other location in which it is has been seen is Radtke's studio.

Self 3 (2006) (fig. 6) is a set of two wooden boxes lined internally with mirrors. The rectangular boxes are also constructed to the dimensions of the artist's height, width, and depth as she reclines. Unlike Deflated, one end of each of the boxes is left open, revealing an interior space. This work was a collaborative effort with a fellow artist and friend of Radtke's, Myra Silva. Radtke commissioned Silva to build three pairs of boxes for Self 1 (fig. 4), Self 2 (fig. 5), and Self 3. The completion of the boxes included taking Radtke's measurements, harvesting the wood, constructing the boxes, lining the interior with mirrors and finishing the wooden surfaces. This effort was collaborative as Radtke assisted with the harvesting of the wood in addition to being present for her measurements to be taken.

Each pair of mirrored boxes is unique with respect to the other pairs, through the construction of the boxes and material. For instance, one box of Self 2 has only four surfaces, which creates an open outline of a rectangle rather than an enclosed box. In terms of material, each pair is made from a different type of wood. Self 3 is made from 
ash and has been exhibited with a sheet of liquid vinyl applied over it while the pair of boxes lays on the floor with the open ends facing the ceiling. But Self 1 and Self 2 are made from ambrosia maple and are typically exhibited in an upright position.

Self 3 was included in this exhibition for a number of reasons. First, it is representative of Radtke's use of a range of materials with the inclusion of wood and mirrors. Second, it was the most practically accessible of the series. One pair (Self 2) is in a private collection in Birmingham, Alabama and the other pair (Self 1) is in Radtke's home; Self 3 is stored in her studio. Another reason this pair appealed to me is the options of presentation: Radtke does not have a preferred positioning for this pair. In previous exhibitions this pair has been laid on the floor but the possibility of the pair standing was more compelling to me. By standing, viewers only have to approach or pass the mirrored boxes to engage with the work rather than peering down into them. I was also captured by the possibility of creating an element of surprise for viewers and strategically creating a corner with the freestanding boxes. I decided to place one of the boxes facing Ghost (wall) and one box facing the wall of windows that overlook the campus, which puts the wooden surfaces facing the entrance of the gallery. My intention behind the placement was to generate the potential of a conversation between viewers and two works of art (Ghost (wall) with Self 3) and viewers with art and nature (Self 3 and the scenery of the campus).

The use of mirrors to line the inside of the boxes creates a complex dialogue with the viewer. Mirrors and studying one's own image is commonplace for most individuals but typically a private endeavor. Here, Radtke creates a semi-private environment as she encloses the mirrors on themselves and invites the viewer into what is fashioned in the dimensions of her personal space. An air of displacement lingers from the presence of 
five reflective surfaces bouncing images off of each other, creating confusion and uncertainty. The inclusion of mirrors also suggests that the work is incomplete without the viewer while also depending on the environment it is situated within.

Thoughts of death (finality) and eternity (continuous) are also prompted in Self 3 . A wooden box constructed to Radtke' specific dimensions alludes to a coffin and ultimately death but the trace of her body is illuminated by a series of mirrors. The reflectivity caused by the mirrors is never ending and projects outwards as if to defy its space, and at last, death.

Curl (2008) (fig. 7) is another pair of wooden boxes specific to the dimensions of Radtke's body as she is curled, similar to Ghost (wall) and Pink (wall). Here the two short ends of the boxes are left exposed, creating a tunnel-like effect. From inside the boxes shattered, tempered glass is poured out. The amount of glass is equal to Radtke's body volume. The connection between the containers sizes and the specific amount of their contents with Radtke's body can be interpreted as symbolic of the aftermath of a personally devastating situation.

As Curl is displayed on the ground, it keeps a very low profile but projects a strong presence as the heaps of broken glass reflect light. This work is dangerous with the sharp, jagged slivers of glass, which has no barrier from viewers. It threatens to harm those who come too close. But the heaps of broken glass are also attractive and alluring as they brilliantly sparkle in the light. These contradictory themes of attracting and resisting are present in other works included in this exhibition but magnified most in Curl.

This work is also one in a series of three that are individual but closely related, all of which are wooden frames constructed to Radtke's body in different positions. Broken 
tempered glass is intentionally poured in a way that also responds to its environment and unique situations making no two installations of these works identical. Curl, much like Self 3, was included because it was the easiest to borrow for this exhibition. The other two works in the series have been purchased; the Speed Art Museum owns Crouch (fig. 8) and Reach (fig. 9) is in a private collection in Louisville, Kentucky. However, Curl is still in the possession of Radtke.

Trace of a Body was created with the venue and expected audience in mind. Because it was installed in a fine arts department's university gallery, I was able to include works with a higher level of comfort. For instance, I did not have to put stanchions or place a barrier around Curl in order to dictate a distance from which viewers had to study the work. I expected that most people visiting this exhibition would be adults (university students, staff, and faculty) or accompanied by an adult and thus cognizant of how to interact, more specifically not physically interact, with broken glass. Similarly, I did not install a barrier around Self 3 for the same reason. I also felt more confident to include Pink (wall) 8 since I have had many meaningful conversations concerning themes of gender and age at the University of Louisville. 


\section{CHRIS RADTKE AND RECENT ART HISTORY}

\section{Introduction}

When I asked about artists she looks to, she identified artists including Donald Judd, Eva Hesse, Agnes Martin, Robert Smithson, and Frank Stella. She shared that she gleans aspects from each of these artists, in addition to artistic movements of Minimalism and Post-minimalism. ${ }^{1}$ While Radtke is uninterested in being siloed into a movement of art history, connections between her work and work of artists from the $20^{\text {th }}$ and $21^{\text {st }}$ centuries are evident. She is singular in her inquiry but there is a history of the use of geometry, installation, and materials that she employs. Her work converses with the work of Minimalists (Donald Judd) and Post-minimalists (Eva Hesse), as well as feminist theory and identity as seen in work by contemporary artists (Maya Lin). The square and rectangular shape of her works is linked to Minimalism while the material she uses is reminiscent of Post-minimalism. She incorporates imagery that is traditionally masculine but overhauls it by studying herself, as an autonomous woman. The result is a complex collection of work that speaks to the self, physically and personally.

\section{Minimalism}

Christopher Want, art-historian and theorist, defines Minimalism as, "[A] term used in $20^{\text {th }}$ century, in particular from the 1960 s, to describe a style characterized by an impersonal austerity, plain geometric configurations and industrially processed

${ }^{1}$ Chris Radtke, interview with the author, February 9, 2015. 
materials. ${ }^{23}$ From this definition it can be assumed that Minimalist art is emotionally detached in material, assembly, and presentation. The artists' personal touch and unique mark, which is traditionally revered in the history of art, is eradicated. The meticulously constructed series of boxes by American artist Donald Judd (1928-1994) exemplify this definition (fig. 10). The boxes are perfectly symmetrical and made from industrial, massproduced material. They are solid with a dominating presence and superficially impersonal, cold.

The manner in which Judd's work is displayed also defies traditional notions of art, particularly definitions of sculpture and painting. Some of Judd's works are displayed on the floor; others are mounted to a wall (fig. 11). Richard Shiff, art historian, speaks to the unconventionality of Judd mounting his geometric forms to the wall as he relates them to "drawers that stick out of shelving units." ${ }^{24}$ Shiff also admits the challenge of mentally processing these types of works never subsides as they challenge traditional notions of painting and sculpture:

"This particular combination of painting-against-the-wall and sculpturesin-space doesn't fit easily into either of these art traditions, and the curious thing is that the way in which this piece isn't like either painting or sculpture dominate the ways in which it might seem like painting or like sculpture. $" 25$

Judd's work is both simple and chaotic. It is reduced to rudimentary geometry and clean lines but radical in its presentation as the wall is used as the ground and the traditional pedestal for sculpture is irrelevant. It defies gravity and demands a reconsideration of space.

${ }^{23}$ Christopher Want, "Minimalism," Grove Art Online, Oxford Art Online, Oxford University Press, accessed February 14, 2015. http://www.oxfordartonline.com.echo.louisville.edu/subscriber/article/grove/art/T058397. ${ }^{24}$ Richard Shiff, "Specificity," in The Writing of Donald Judd, ed. Allan Antliff, (Marfa, Texas: Chinati Foundation, 2009), 79.

${ }^{25}$ Ibid., 80 . 
Each of the works in the exhibition Trace of a Body comments on Judd's squares and rectangular boxes. In Ghost (wall) (fig. 1) and Pink (wall) (fig. 2) series of boxes cover expanses of walls, much like traditional paintings, but jut out like the drawers of shelves that Shiff explains. While the works come off the walls and form another dimension of space, their relationship with gravity is different from Judd's. Radtke's forms now submit to the gravitational pull, rather than rigidly defying it. And although Radtke's containers are precise and use commercial materials, mass-produced, they diverge from Judd in their flexibility, adaptability, and symbolism. Additionally, they are constructed reflecting Radtke's body size, a major shift away from ideas that Judd was using in his artwork.

Radtke's Curl (fig. 7) is also reminiscent but opposite of Judd's boxes. The sturdy, rectangular boxes are left open at the ends as they rest directly on the ground. While Curl is a pair of stiff boxes, it is wood built from lumber personally harvested for its apparent, individual flaws. Here she cancels Judd's air of austerity and anonymity as she brings a sense of life and personal variety into conversation with her more expressive materials.

\section{Post-minimalism}

In the 1960s, at the same time as Minimalism, the divorce from human touch and impersonality was countered by with the work of Post-minimalist artists. Doug Singsen, art historian, elaborates on the issues springing from Minimalism that later artists are determined to remedy:

"Post-minimalists adopted a de-centered, flexible, open structure in their work; elevated the process of creation over its end result; employed techniques and materials that incorporated contingency and ephemerality; 
used the artist's body and the natural and built environments as raw materials; and introduced signifiers of femininity into their work."26

Responding to the sterile and oppressive art of Minimalists, artists revived the importance of the body and human connection in art making.

An exemplary Post-minimalist artist is German born American artist Eva Hesse (1936-1970). In 1965 while living in Germany for an artist residency, Hesse first started making relief sculptures, including Ringaround Arosie (1965) (fig. 12). ${ }^{27}$ These works are the product of industrial cast-off and a variety of techniques. ${ }^{28}$ From the refuse and variety used by Hesse evolves anthropomorphized imagery. Jo Applin, art historian, describes Ringaround Arosie this way: "There is something so ludicrously bodily about this work, while at the same time it is so clearly not of the body, for there is no one body part this work could be seen as 'depicting'., ${ }^{29}$ Members of the artistic community, including American artist Mel Bochner, initially found Hesse's work detached, perhaps similarly to works by Minimalists artists. However, Briony Fer argues: "Contradictorily, then, to be in the picture is to be out of the pictures. What seems interesting now is not simply how the body comes to be placed in the work, but how it does so only to expose a fundamental absence in the bits and pieces of subjectivity that seem to get detached in the process. ${ }^{30}$

\footnotetext{
${ }^{26}$ Doug Singsen, "Post-minimalism," Grove Art Online. Oxford Art Online, Oxford University Press, accessed April 2, 2015.

http://www.oxfordartonline.com.echo.louisville.edu/subscriber/article/grove/art/T209079 1.

${ }^{27}$ Susan Fisher Sterling, "Off the Wall," in Eva Hesse 1965, ed. Barry Rosen, (London: Yale University Press, 2013), 8.

28 Ibid., 13.

${ }^{29}$ Jo Applin, "C-Clamp Blues: The Relief Works of Eva Hesse," in Eva Hesse 1965, ed. Barry Rosen, (London: Yale University Press, 2013), 43.

${ }^{30}$ Briony Fer, "Objects Beyond Objecthood," Oxford Art Journal 22:2 (1999): 29.
} 
Hesse's abstraction combined with her material, such as latex and liquid rubber, creates this dynamic sense of the body, seen in Contingent (1969) (fig. 13). ${ }^{31}$ Hesse treats latex and liquid rubber in a manner that is suggestive of skin, due to its pliability and color. Fer asserts that these works by Hesse evoke imagery of "shed skin with raw unfinished edges. ${ }^{, 32}$ While Contingent is a series of vertically hanging sheets and simple lines, during the artistic process the material Hesse used responded organically and morphed over time. They are stretched while one panel even bends in response to the floor. It is wrinkled and wavy suggesting stress and age.

Much like Judd, Hesse uses industrial material to create series of shapes that also intrude into space, away from the wall. But Hesse's material is not static. It gives evidence of manipulation, stress, and growth. These qualities of responding to gravity and metaphors for skin are also apparent in Radtke's Deflated (fig. 3). The plastic material corresponds to the latex used by Hesse as it is smooth and solid but creates wrinkles and responds to gravity. It also, subtly, protrudes into space, away from the wall. And because the work's size is Radtke's height and width, one can almost envision her body in the work, as a type of cocoon or additional layer of skin. The orange transparent material of Deflated, while inorganic and artificial, also creates a warm energy, as opposed to the natural colors of Hesse's work. Deflated's color is both alarming and welcoming. The paradox is subtle and complicated, suggesting how Radtke understands herself, or how she wants viewers to understand her.

\footnotetext{
31 Ibid., 32.

${ }^{32}$ Ibid.
} 


\section{Feminism}

Simone de Beauvoir writes in her seminal book The Second Sex about how women have been perceived, dictated, and treated throughout time. ${ }^{33}$ Tongue in cheek she emphasizes, "Woman has ovaries, a uterus; these peculiarities imprison her in her subjectivity, circumscribe her within the limits of her own nature. It is often said that she thinks with her glands." ${ }^{34}$ Beauvoir goes on to explain that man also thinks with his glands but a woman's physicality has always been the seemingly inescapable source of her degradation.

As Beauvoir does, Radtke contests this notion by making her body the superior standard for her sculptures; the strongest example is Pink (wall) (fig. 2). Here she creates clear vulvar imagery with putting a vibrant pink streak down the crisp white mesh forms. In this work submission to gravity creates suggestive folds that are reminiscent of female genitalia, as discussed in "Trace of a Body Exhibition Details". The mesh's submission to gravity should not be confused as representing a woman's submission, rather the opposite. It is an empowerment as she claims authority over woman's body and celebrates it, much like Judy Chicago's Dinner Party (1979) (fig. 14).

Similarly to Hesse and Post-minimalists, Radtke uses the masculine arena of Minimalism to study and present herself in addition to feminist discourse. Radtke adjusts the materials and dimensions of her sculptures to be in direct conversation with not only her body but also with viewers. The mirrors in Self 1 (fig. 4), Self 2 (fig. 5), and Self 3 (fig. 6) all provide direct access and dialogue between the viewer, the art, and to a degree the artist. The wooden boxes in this series are the dimensions of Radtke's body as she stands tall but the openness and interior mirrors invite viewers into this space and suggest

${ }^{33}$ I would argue these conditions are still relevant.

${ }^{34}$ Simone de Beauvoir, The Second Sex (New York: Knopf, 1952), xxxix. 
completeness of the work achieved through the interaction. This dialogue and connection between art and people powerfully brings humanity back into importance that Minimalism had previously abandoned.

\section{Another Connection}

The symbolism and significance of material, specifically glass in relation to the body and personal identity, is compellingly illustrated in the work of Maya Lin, American architect and artist (b. 1959). Her outdoor installation work Groundswell (1993) (fig. 15) uses forty-three tons of previously broken automobile glass to form heaps that resemble mounds in the earth or rising waves of the ocean. Commissioned by the Wexner Center for the Arts, Lin spontaneously installed the massive amount of shattered glass over three levels, creating a dynamic and treacherous terrain, to be admired only from afar. $^{35}$

Without prior training in glass art Lin admits that the appeal of the material is multifold. First, the challenge of intentionally placing broken glass in a high-traffic area of a university campus provides an element of inherent danger. The now broken, threatening glass was previously relied upon for a protective function in automobiles. Lin grants this damages material a second life that exudes beauty, mystery, and vulnerability as it dazzles in the sunlight and admits defeat in its brokenness. At the same time it is offputting, as barriers are required to protect viewers from physically interacting with the work. Second, despite physically distancing the body, she uses broken glass as a platform to explore and discuss identity. Throughout her career she has been confronted with racism and sexism as an Asian woman. Exploring boundaries, geographically and

${ }^{35}$ Maya Lin, Boundaries (New York: Simon \& Schuster, 2000), 6:14. 
socially, is a frequent theme in her work. ${ }^{36}$ In Groundswell she requested two different types of glass (clear and green) to represent her Eastern and Western heritages. ${ }^{37}$ The mixing of the two glasses is a representation of her life and values as she has constantly wrestled to find her identity in both.

Radtke also uses broken tempered glass as a symbol of her identity. It is a physical representation of her body's volume and emotional response to personal devastation, which challenged Radtke's understanding of herself. While the glass in Curl was industrially manufactured, as is the glass of Groundswell, Radtke broke it herself in a meditative effort. As the glass is mounded inside the work's wooden box and pours out onto the ground, it also dazzles in the light as it threatens harm in the viewers space. Like the energetic and alarming color of Deflated, the broken glass of Curl is alluring but hazardous. It is a familiar material that is can be quickly discarded and forgotten about as it represents a disruption in plans, a failure, a disgrace. But Radtke, in addition to Lin, champions it. She brings it into the fine arts space and uses it to symbolize herself, something to consider closely with caution.

\section{Conclusion}

Radtke's work is undeniably at a crucial intersection in the history of art. Her well-constructed but flexible forms, suggestive materials, and non-figural but representational symbols are in dialogue with Judd, Hesse, and Lin as she champions the power of the body, identity, and human connection in artistic practice. She not only taps into Judd's masculine arena, she uses it as a platform to present herself. Radtke is transparent in the fact that the works she makes are a symbol of her body in size rather

\footnotetext{
${ }^{36}$ Ibid., 2:03.

${ }^{37}$ Ibid., 6:17.
} 
than meaningless dimensions. But she also creates complex dialogues by her use of material. She furthers Hesse's efforts to align art with the body by using mesh and thin plastic that transforms over time. The plastic and broken glass also triggers complicated conversations about her identity and how she wants viewers to understand her as she draws them in while being sure to maintain a mystery and distance through dramatic colors and dazzling glass. Ultimately, she unapologetically puts herself (her body, her life, her power) on display for study and contemplation. 


\section{CONCLUSION}

\section{The What and the Why}

As a curator and emerging museum professional, I am passionate about telling compelling stories and facilitating meaningful conversation, between artists and viewers. These convictions are an integral focus and concern of art centers and museums. Everything, from which artists are represented in collections and temporary exhibitions, to educational programming and community outreach, involves storytellers and dialogue. My curatorial decisions, in this project and others in the past, reflect these passions. I want to exhibit art that is psychologically and emotionally meaningful. I want to form relationships with artists who also share these passions, for my sake, the sake of the institution I am working for, and the community I am working within and I want to give audiences context for the relationships and circumstances that add meaning to the physical objects and installations.

Radtke's position of art grappling with life rather than art for art's sake deeply resonates with me. From my experience, I have noticed that some people experience an intimidation or unjustified dismissal of art that is not purely representational or figural. At first glance Radtke's work brings to the mind no connection to the body. From a purely visual aspect, her work might be deemed challenging to access and understand. I believe that the more people are exposed to art that is non-representational and non-figural, the more comfortable they will feel with it. This is one reason for choosing to curate an exhibition that includes installation art and non-figurative sculpture. 
Radtke asks challenging, important questions. She examines how one quality or set of qualities influences another. There is a constant dialogue between the material and environment of Radtke's art that correlates with life and circumstances. These dialogues encompass themes of the body, how it changes gradually over time, grows, morphs, and shrinks. Emotional tribulation and personal defeat are also touched on. The inherent struggle between elements of biological predetermination and personal choice is a dynamic each person wrestles with. By studying her personal space in the specific manner she chooses, Radtke presents tangibility to these truths. Her art, especially the works selected for Trace of a Body, are autobiographical but also create a format for all to experience personal engagement and self-reflexivity.

\section{After the Exhibition}

In terms of defining success, I failed to establish quantitative criteria, something I wish I had been more diligent with. Rather, I interviewed people to ask what they thought of the exhibition after they visited it. Whether they were friends, family, peers, or strangers, I ask what they honestly thought and felt, of the art and the exhibition. During the course of the exhibition I was required to monitor to all three of the Hite Art Institute galleries and observed how many people wandered through my exhibition in comparison to the exhibitions of the other two graduate students. I noted the amount of time spent in each exhibition. This method of collecting information is deeply flawed and unscientific in terms of statistics, but time is one of the most valuable resources we have and the amount of time spent with anything is indicative of how much value we think a thing or person deserves. I have received only positive feedback in my interviews, of which I am skeptical because I know I still have a lot to learn. 
Reflecting back to my intention of facilitating conversation for visitors initiated by Radtke's work, I would adjust my execution, particularly aspects of the extended labels and educational efforts. I only included three extended labels in the exhibition. Each label was a paragraph dealing with one theme in one work. If given the opportunity, I would write an extended label for each work and draw out multiple themes. I would also modify the tone of the labels to be less didactic and perhaps more conversational. Additionally, I would arrange for Radtke to give a talk in the gallery during the course of the exhibition. These additions would further prompt and facilitate contemplation and conversation past what was actually executed.

A positive consequence of Trace of a Body is the sale of Deflated. Upon returning Radtke's art to her studio she informed me that Deflated has been sold after it was seen in my exhibition. As mentioned previously, this work had not been shown publically prior to this exhibition. During a visit to the exhibition, a curator from New York City took pictures and sent them to a few collectors. Before the end of the day, Deflated had been claimed by a couple in New York City. While I did not work with collectors or galleries to borrow works for the exhibition, I also did not anticipate for the sale of a work. Although I was not present for those particular conversations and transaction this circumstance reinforces another function of curating and the curator's position of being a part of the pulse of contemporary art. 


\section{REFERENCES}

Acord, Sophia Krzys. "Beyond the Head: The Practical Work of Curating Contemporary Art." Qualitative Sociology. 33, 4 (2010): 447-467. Accessed March 25, 2015. doi: 10.1007/s11133-010-9164-y

Alloway, Lawrence. "The Great Curatorial Dim-Out." In Thinking about Exhibitions. Edited by Reesa Greenberg, Bruce W Ferguson, and Sandy Nairne, 221-230. New York: Routledge, 1996.

Applin, Jo. "C-Clamp Blues: The Relief Works of Eva Hesse." In Eva Hesse 1965, edited by Barry Rosen, 40-49. London: Yale University Press, 2013.

Brenson, Michael. “The Curator's Moment.” Art Journal 57:4 (Winter 1998): 16-27.

De Beauvoir, Simone. The Second Sex. New York: Knopf, 1952.

Fer, Briony. “Objects Beyond Object.” Oxford Art Journal 22:2 (1999): 27-36.

Lin, Maya. Boundaries. New York: Simon \& Schuster, 2000.

Radtke, Chris. Interview with the author. Louisville, Kentucky. January 29, 2015.

Radtke, Chris. Interview with the author. Louisville, Kentucky. February 9, 2015.

Radtke, Chris. Interview with the author. Louisville, Kentucky. February 18, 2015.

Shiff, Richard. "Specificity." In The writings of Donald Judd: a symposium hosted by the Chinati Foundation, Marfa, Texas, May 3-4, 2008, edited by Allan Antliff, 79-98. Marfa, Texas: Chinati Foundation, 2009.

Singsen, Doug. "Post-minimalism." Grove Art Online. Oxford Art Online. Oxford University Press. Accessed April 2, 2015.

http://www.oxfordartonline.com.echo.louisville.edu/subscriber/article/grove/art/T 2090791.

Smith, Roberta. “An Alien Sighting on Planet Pittsburgh.” New York Times, May 92008. Accessed September 18, 2013. http://www.nytimes.com/2008/05/09/arts/design/09carn.html?pagewanted=print

Smith, Terry. Thinking Contemporary Curating. New York: Independent Curators International, 2012. 
Sterling, Susan Fisher. "Off the Wall.” In Eva Hesse 1965, edited by Barry Rosen, 6-15. London: Yale University Press, 2013.

Want, Christopher. "Minimalism." Grove Art Online. Oxford Art Online. Oxford University Press. Accessed February 14, 2015.

http://www.oxfordartonline.com.echo.louisville.edu/subscriber/article/grove/art/T 058397. 


\section{APPENDIX A - IMAGES OF RADTKE'S ART}

\section{Images}

All but one of the following images were made by the photographer Sarah Lyon and shared with me by Chris Radtke, taken during previous exhibitions in Louisville. Timothy Mazik took the image of Deflated during the exhibition Trace of a Body.

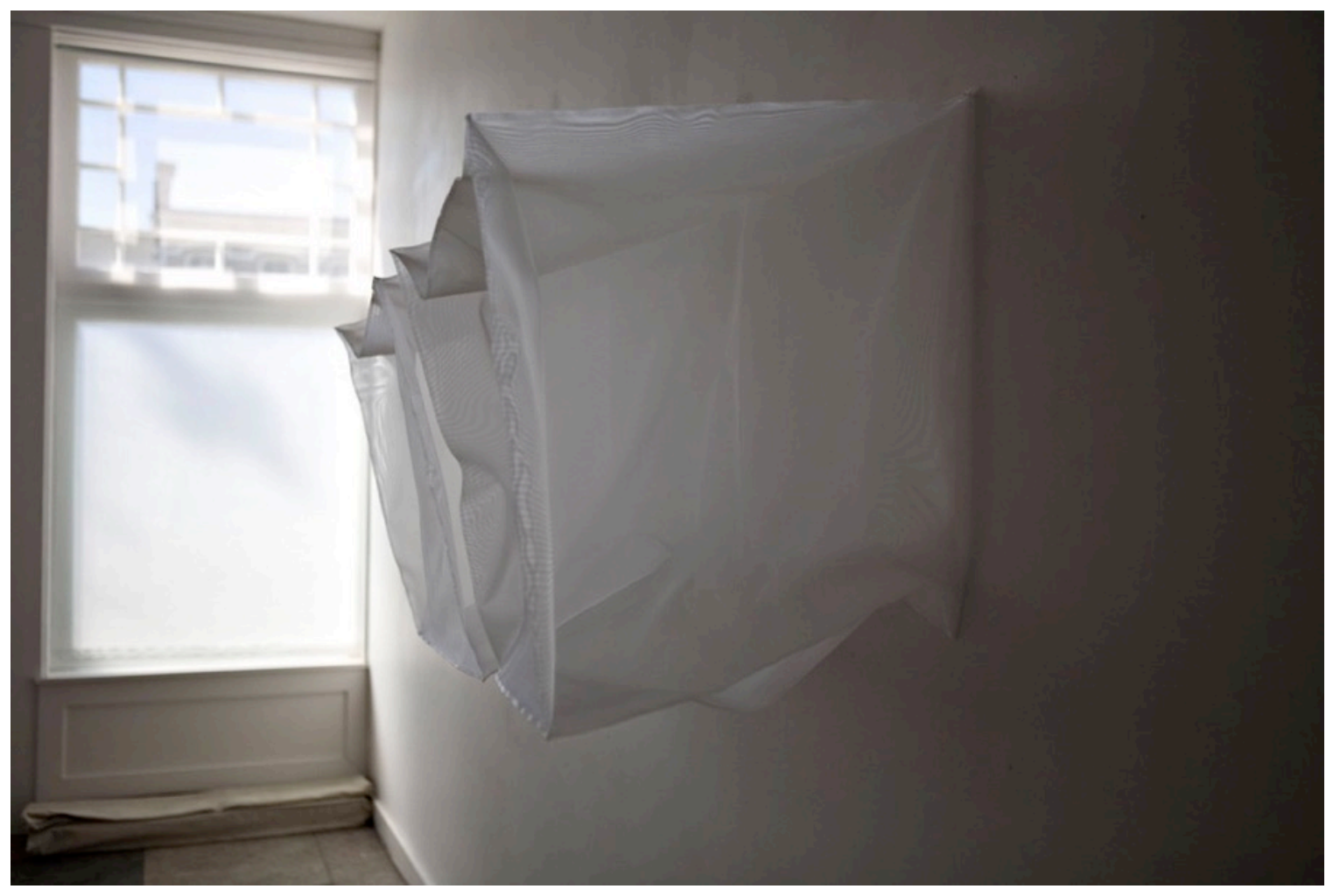

Figure 1: Chris Radtke, Ghost 2 (study), 2009. Nylon mesh, monofilament. 24 x 24 x 22 each. Photograph by Sarah Lyon. 


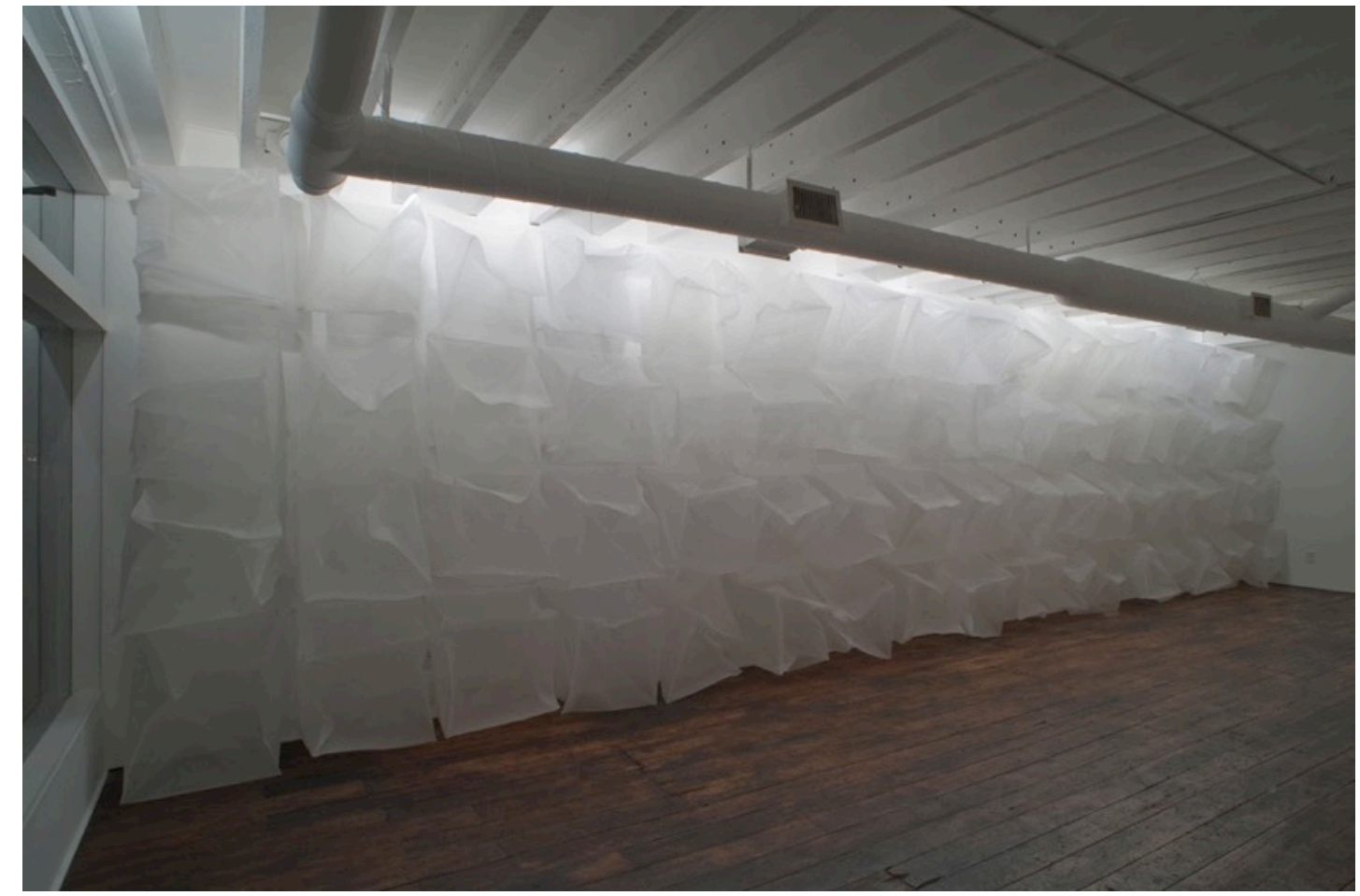

Chris Radtke, Ghost (wall) 68, 2011. Nylon mesh, monofilament. 24 x 24 x 22 each Photograph by Sarah Lyon. 


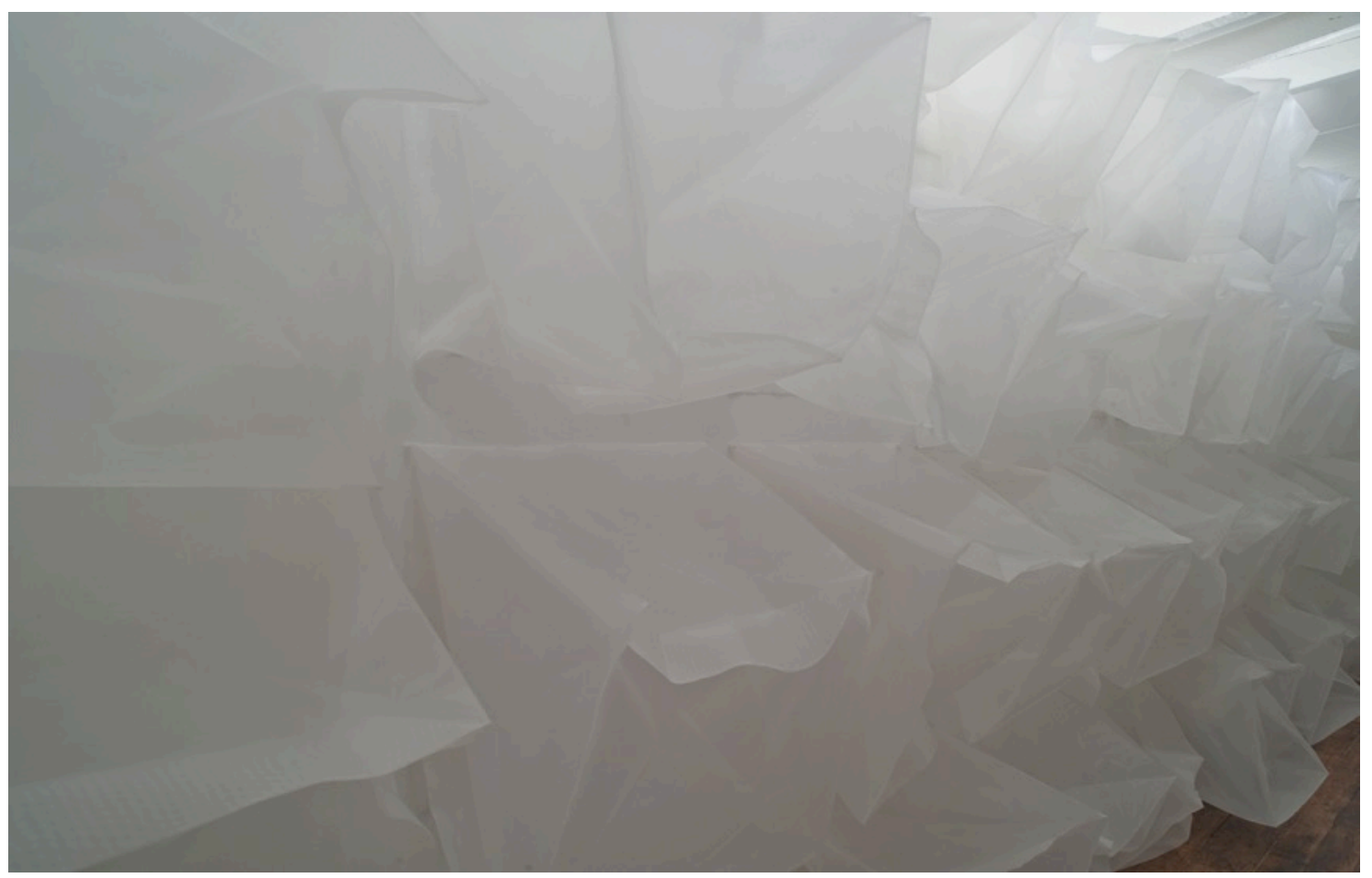

Chris Radtke, Ghost (wall) 68 (detail), 2011. Nylon mesh, monofilament. 24 x 24 x 22 each Photograph by Sarah Lyon. 


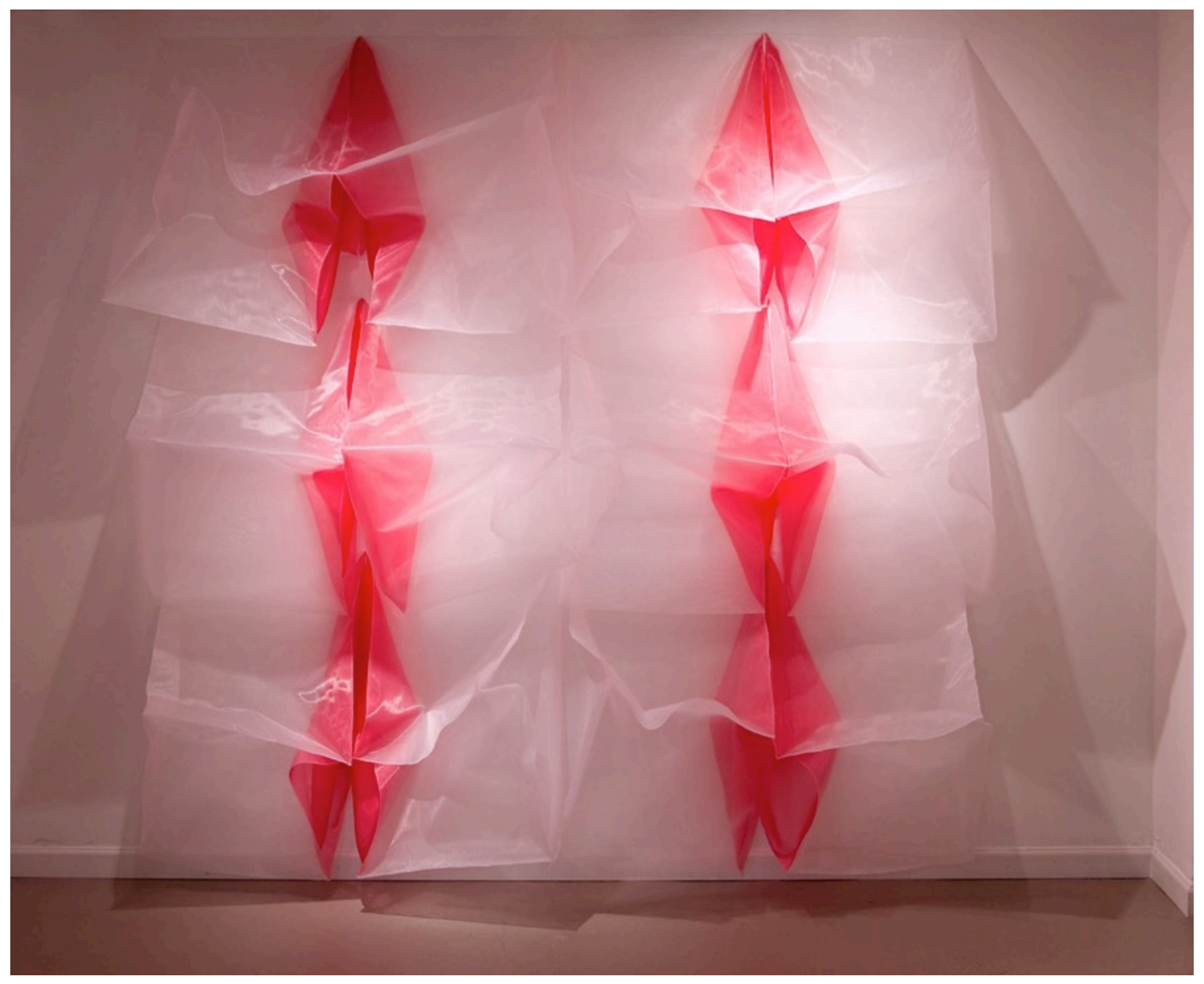

Figure 2: Chris Radtke, Pink (wall) 12, 2012. Nylon mesh, monofilament. 24 x 24 x 22 each. Photograph by Sarah Lyon. 


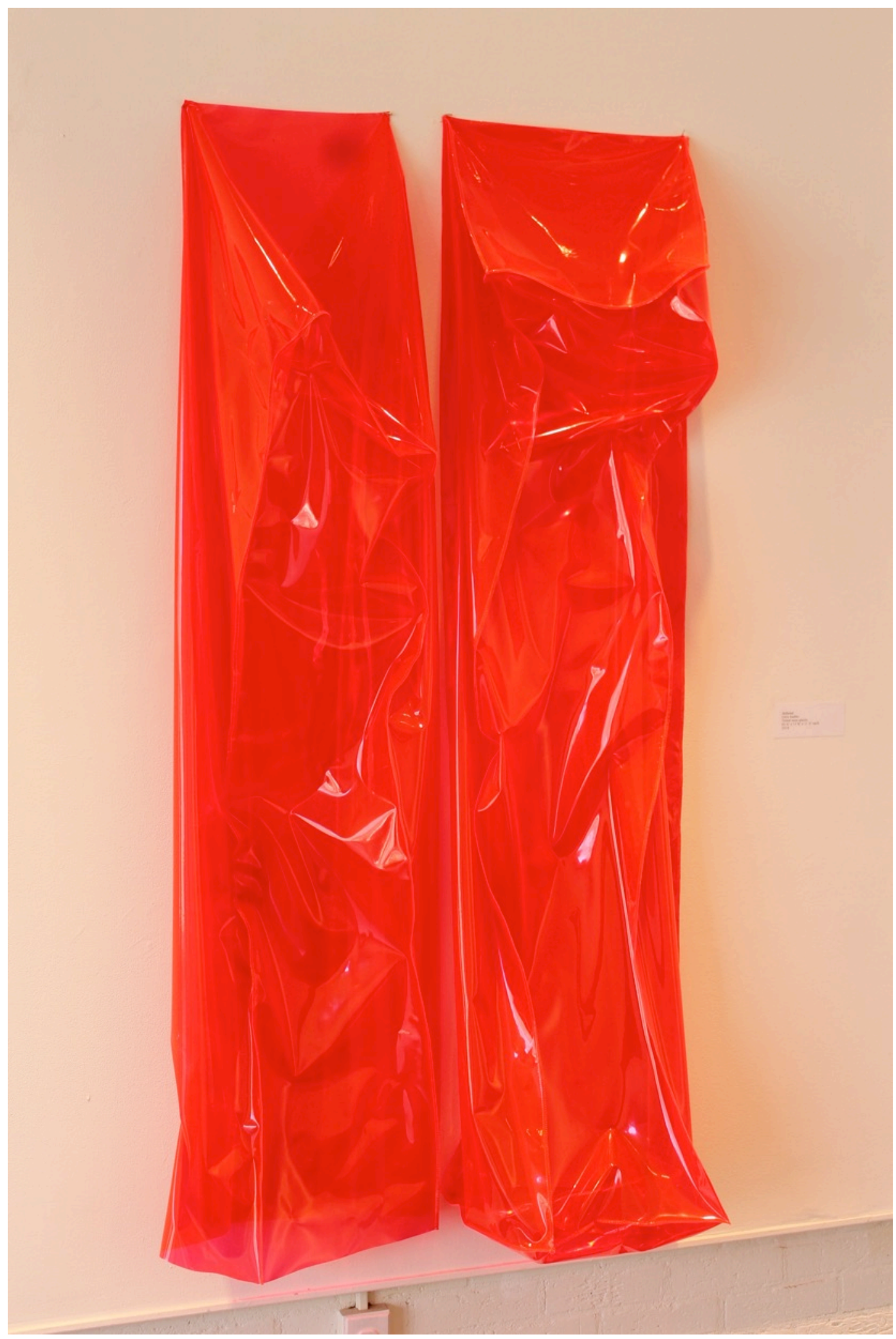

Figure 3: Chris Radtke, Deflated, 2014. Tinted neon plastic. 65 1/2” x 15 3/4" x 11 1/2” each. Photograph by Timothy Mazik. 


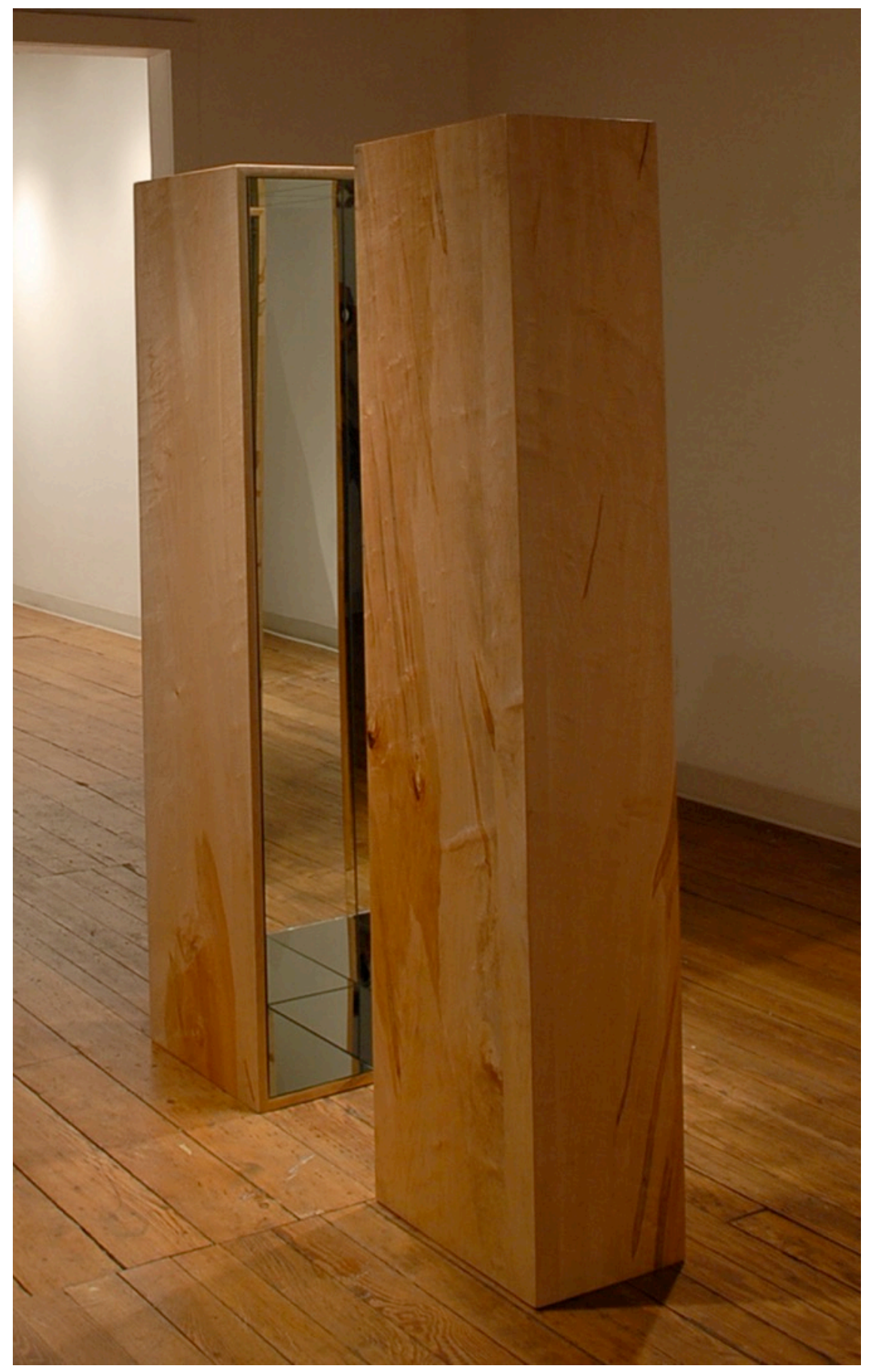

Figure 4: Chris Radtke, Self 1, 2006. Ambrosia maple, mirror. 15 1/2” x 15 3/4” x 9 1/2" each. Photograph by Sarah Lyon. 


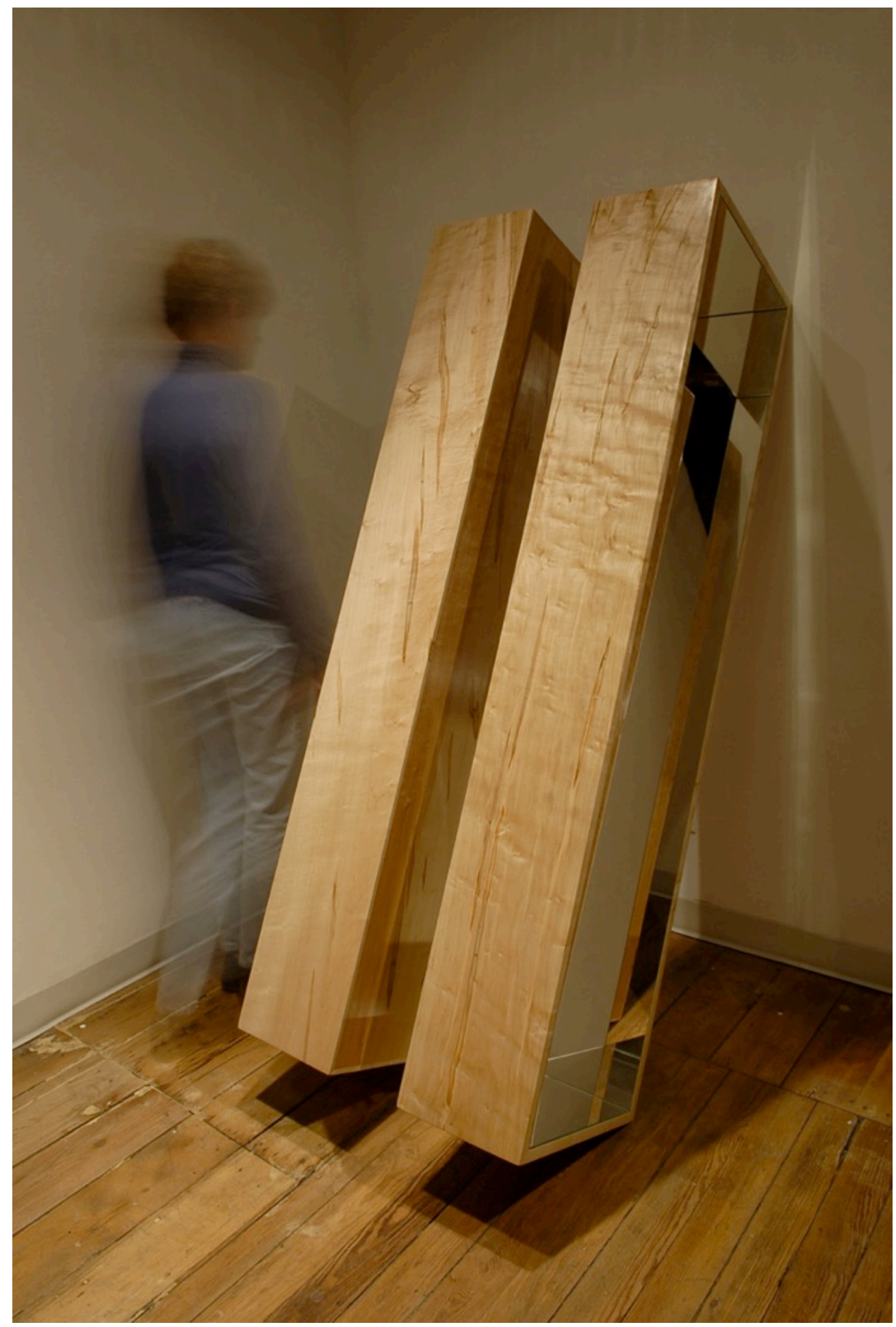

Figure 5: Chris Radtke, Self 2, 2006. Ambrosia maple, mirror. 15 1/2” x 15 3/4" x 9 1/2" each. Photograph by Sarah Lyon. 


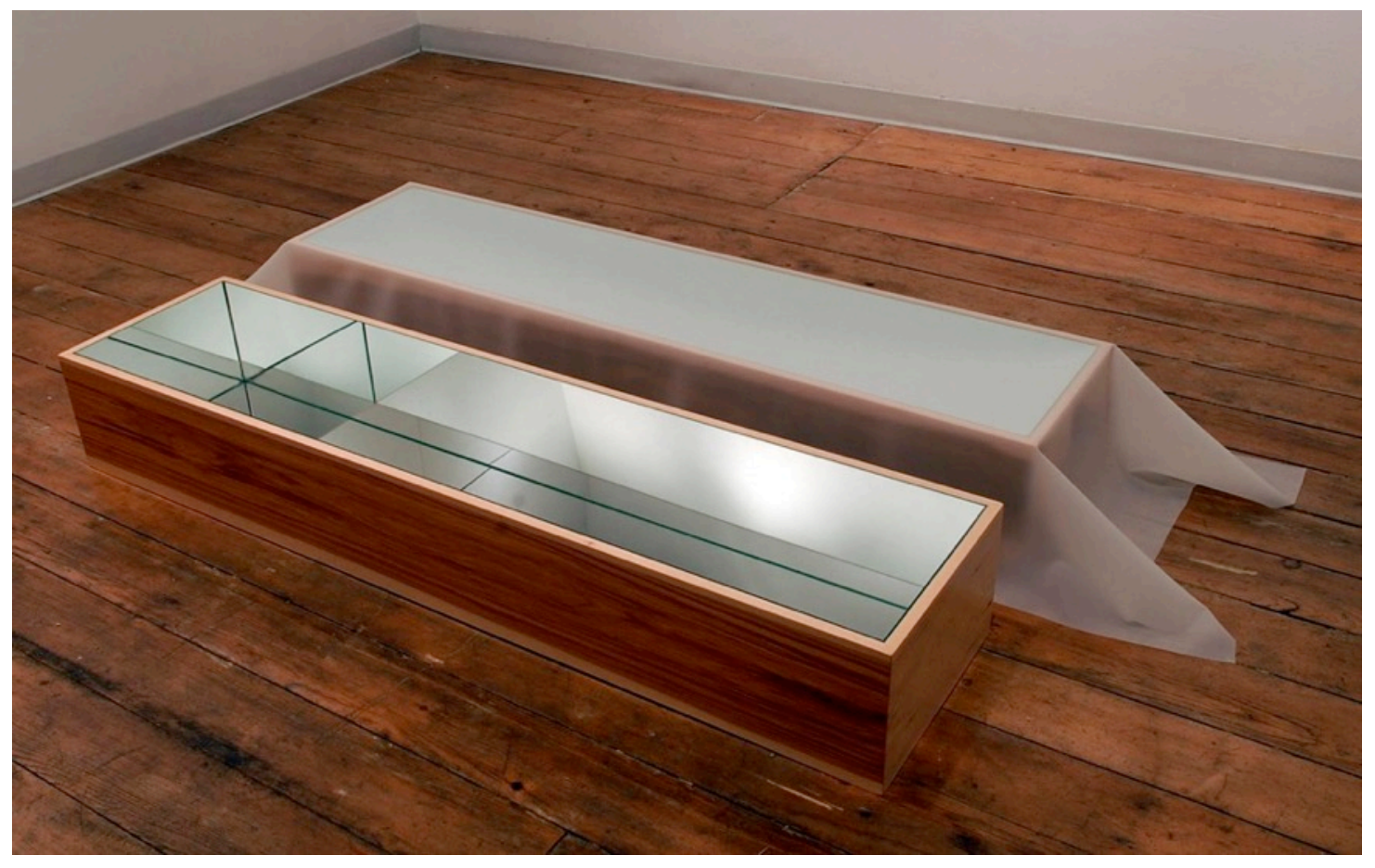

Figure 6: Chris Radtke, Self 3, 2006. Ash, mirror, liquid vinyl. 15 1/2” x 15 3/4" x 9 1/2" each. Photograph by Sarah Lyon. 


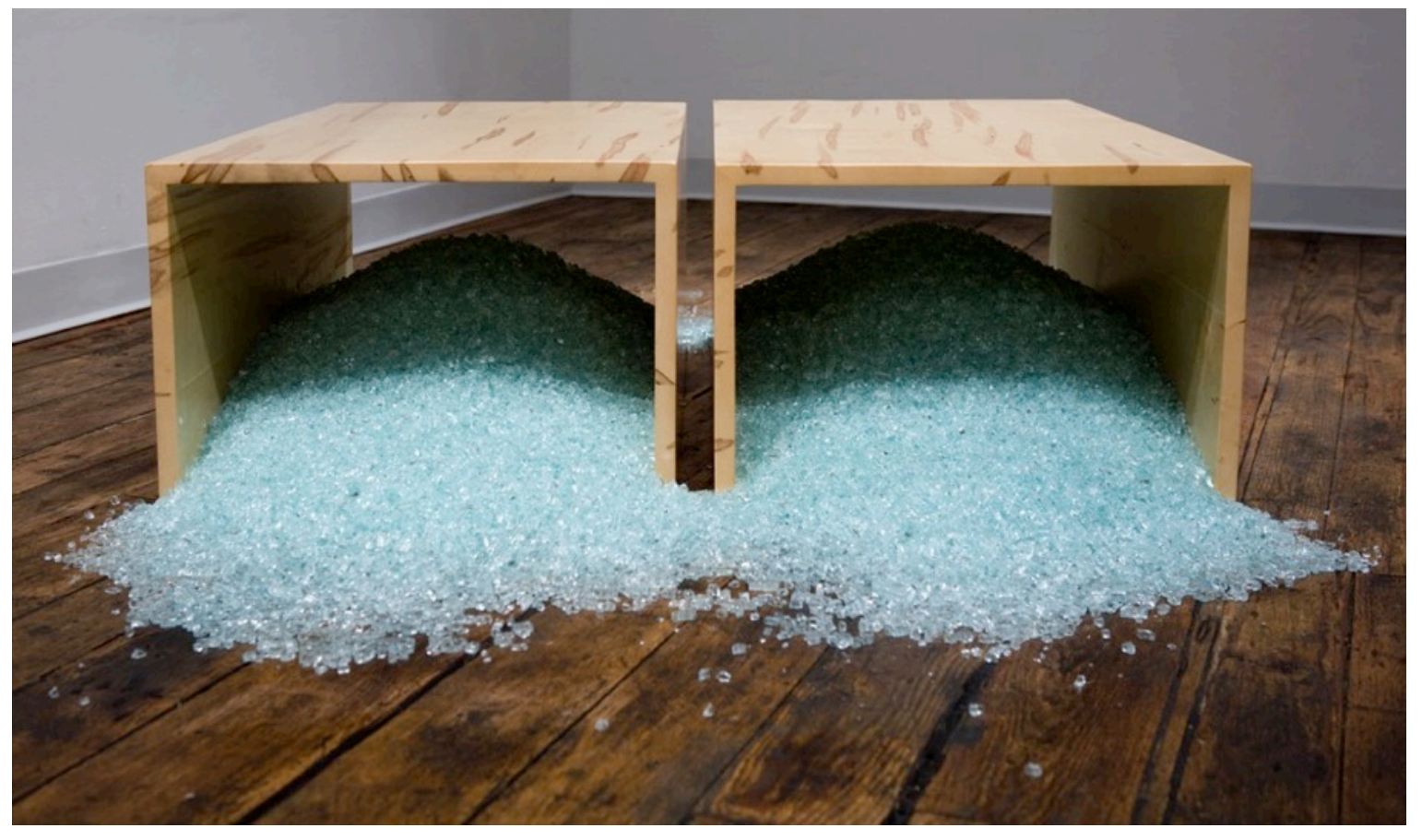

Figure 7: Chris Radtke, Curl, 2008. Box elder, shattered tempered glass. 13 3/4” x 20” x 35 1/2” each. Photograph by Sarah Lyon. 


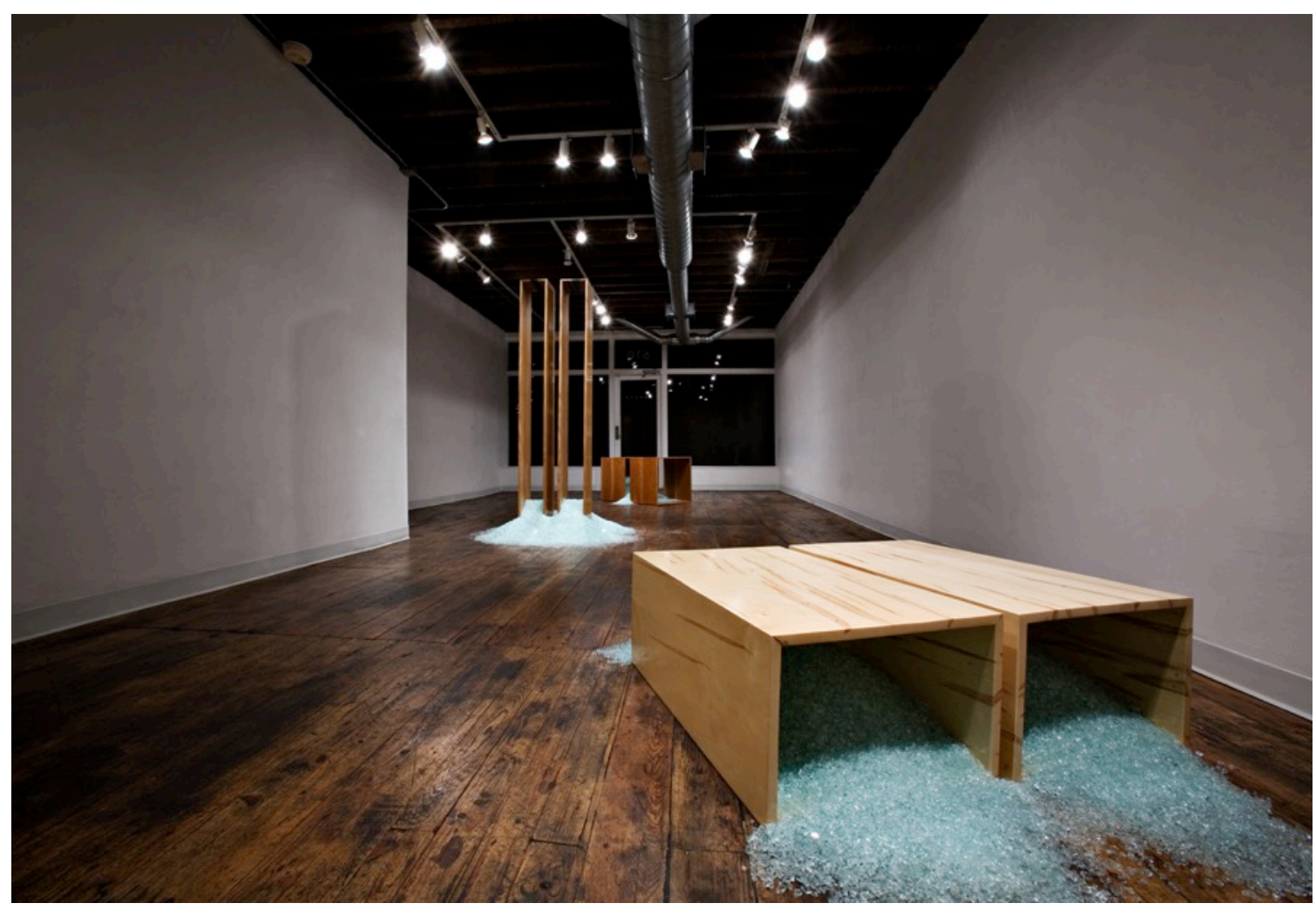

Chris Radtke, Curl, install shot, 2008. Box elder, shattered tempered glass. 13 3/4" x 20" x 35 1/2" each. Photograph by Sarah Lyon. 


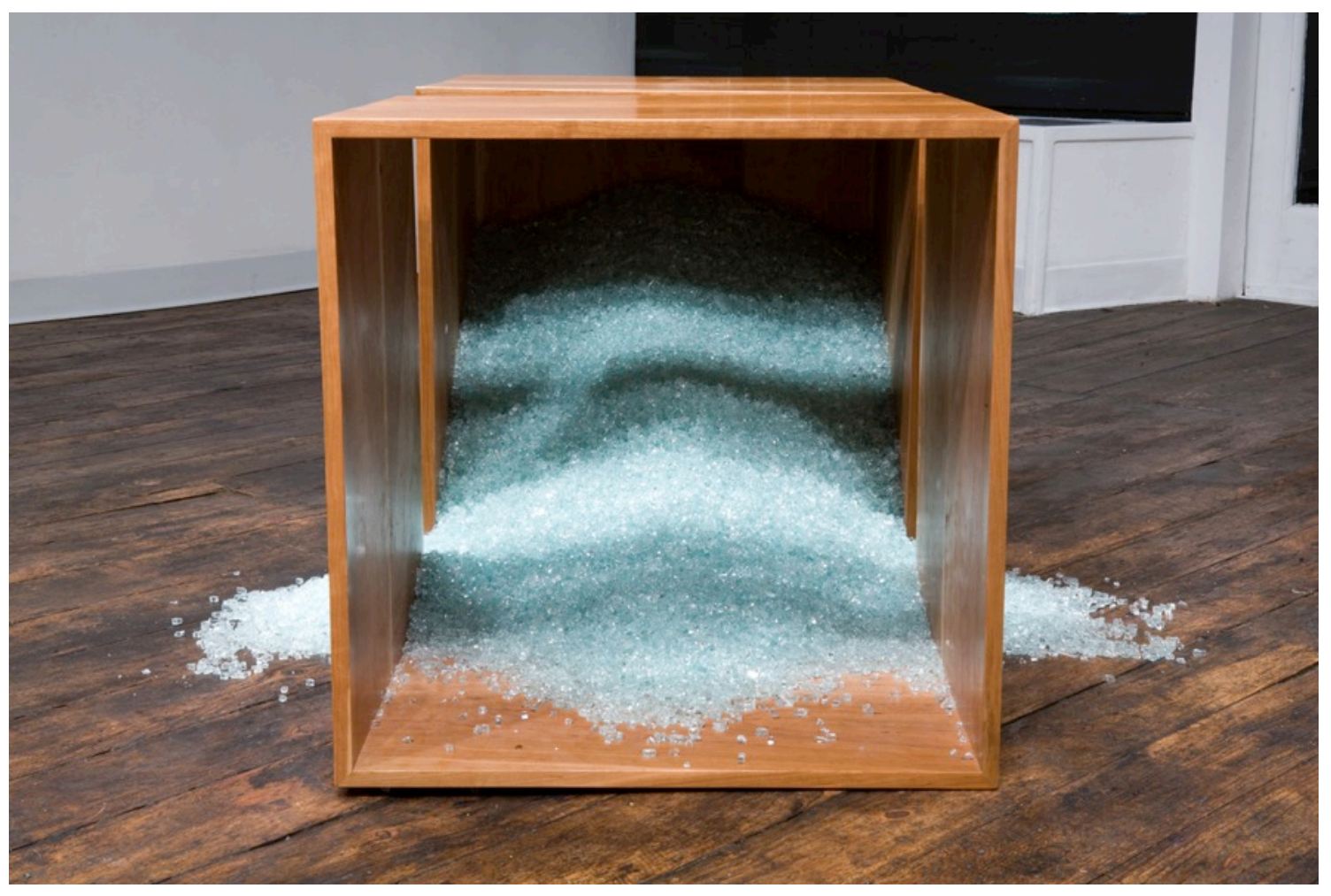

Figure 8: Chris Radtke, Crouch, 2008. Cherry, shattered glass. Photograph by Sarah Lyon. 


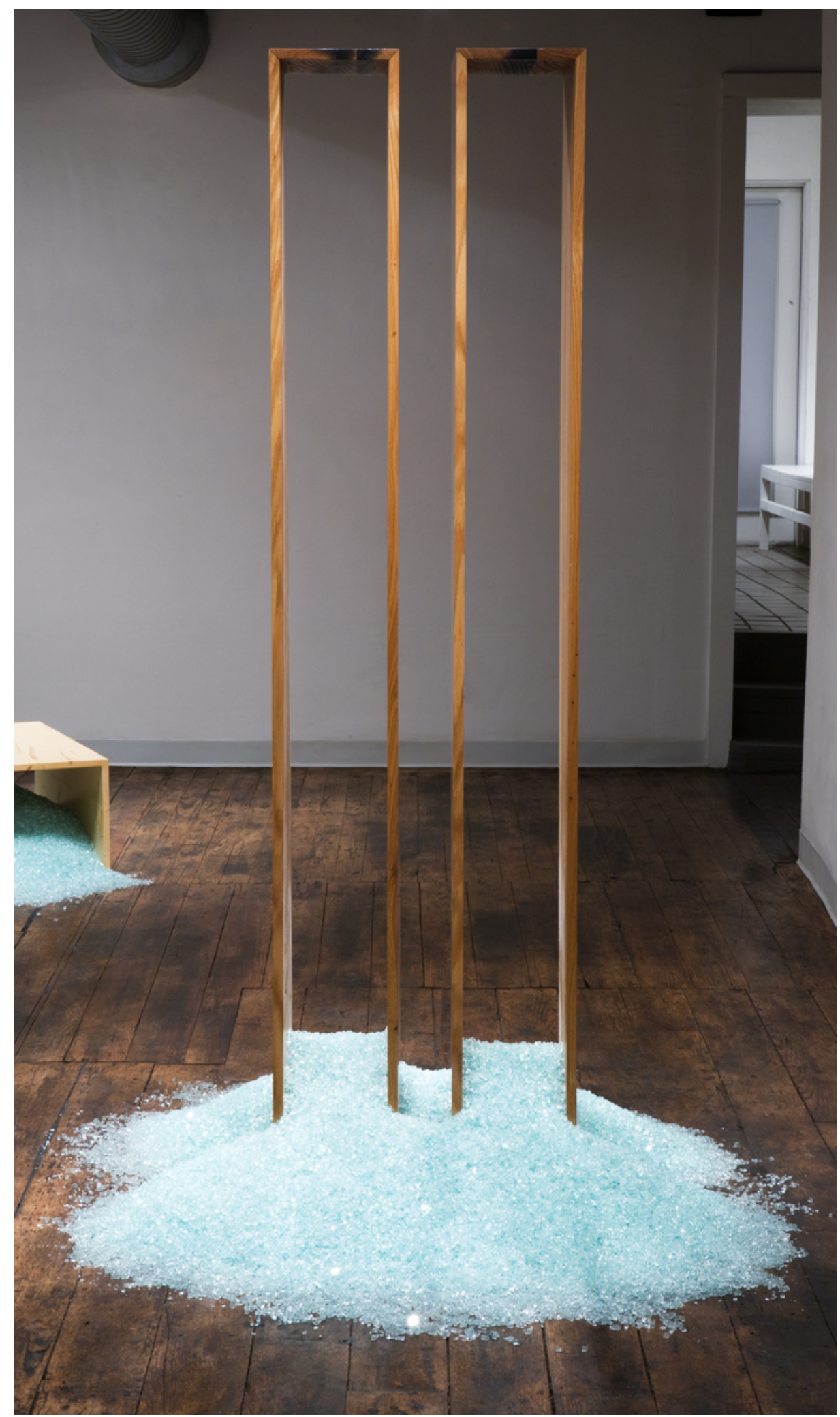

Figure 9: Chris Radtke, Reach, 2008. Oak, shattered tempered glass. Photograph by Sarah Lyon. 
APPENDIX B - TRACE OF A BODY EXHIBITION INSTALLATION IMAGES

\section{Installation Shots}

All images were taken by Timothy Mazik during the exhibition Trace of a Body in Gallery X in Schneider Hall in the Hite Art Institute at the University of Louisville. March 12 - April 5, 2015.

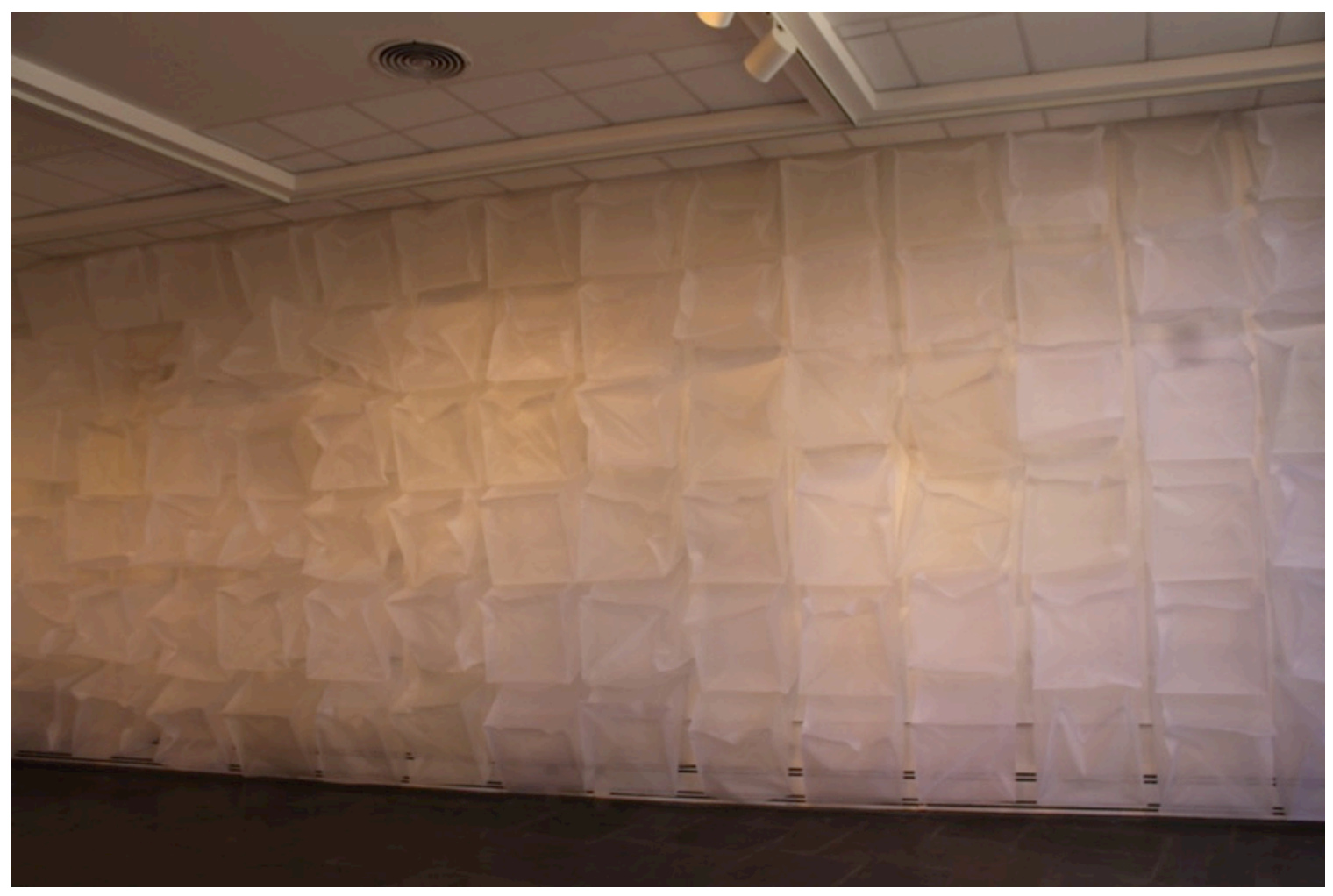




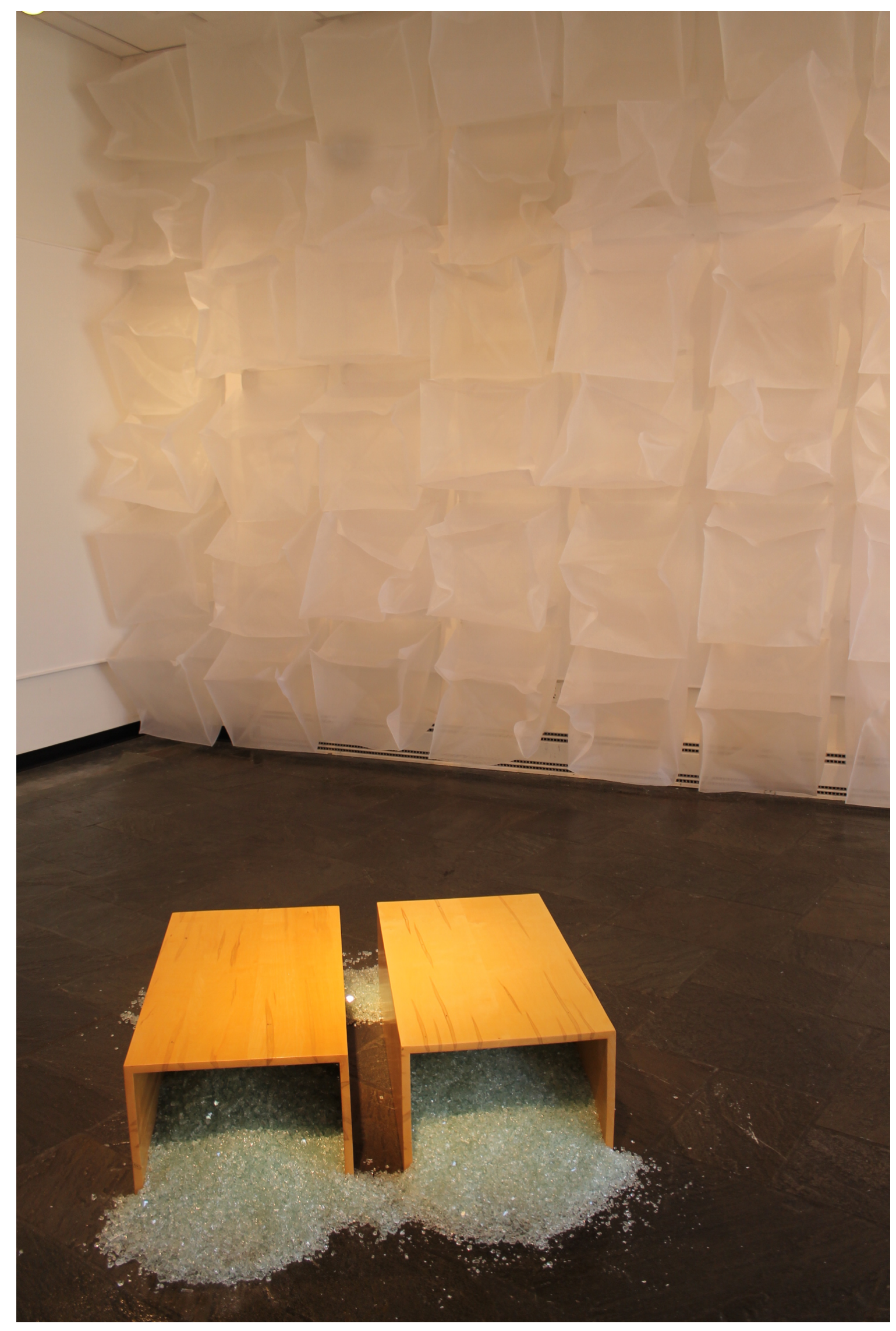




\section{Trace of a Body Work by Chris Radtke Curated by Bailey Mazik}



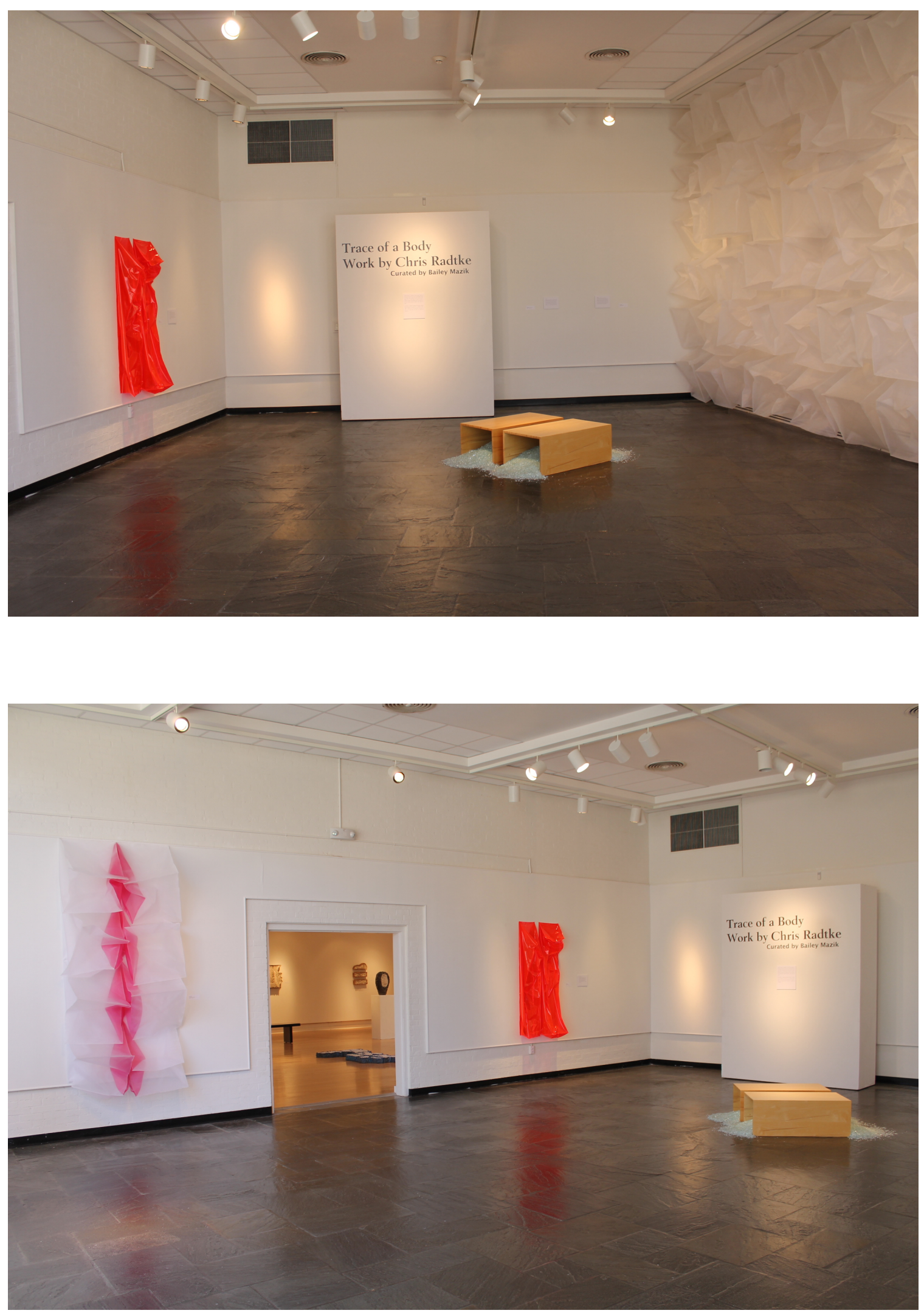


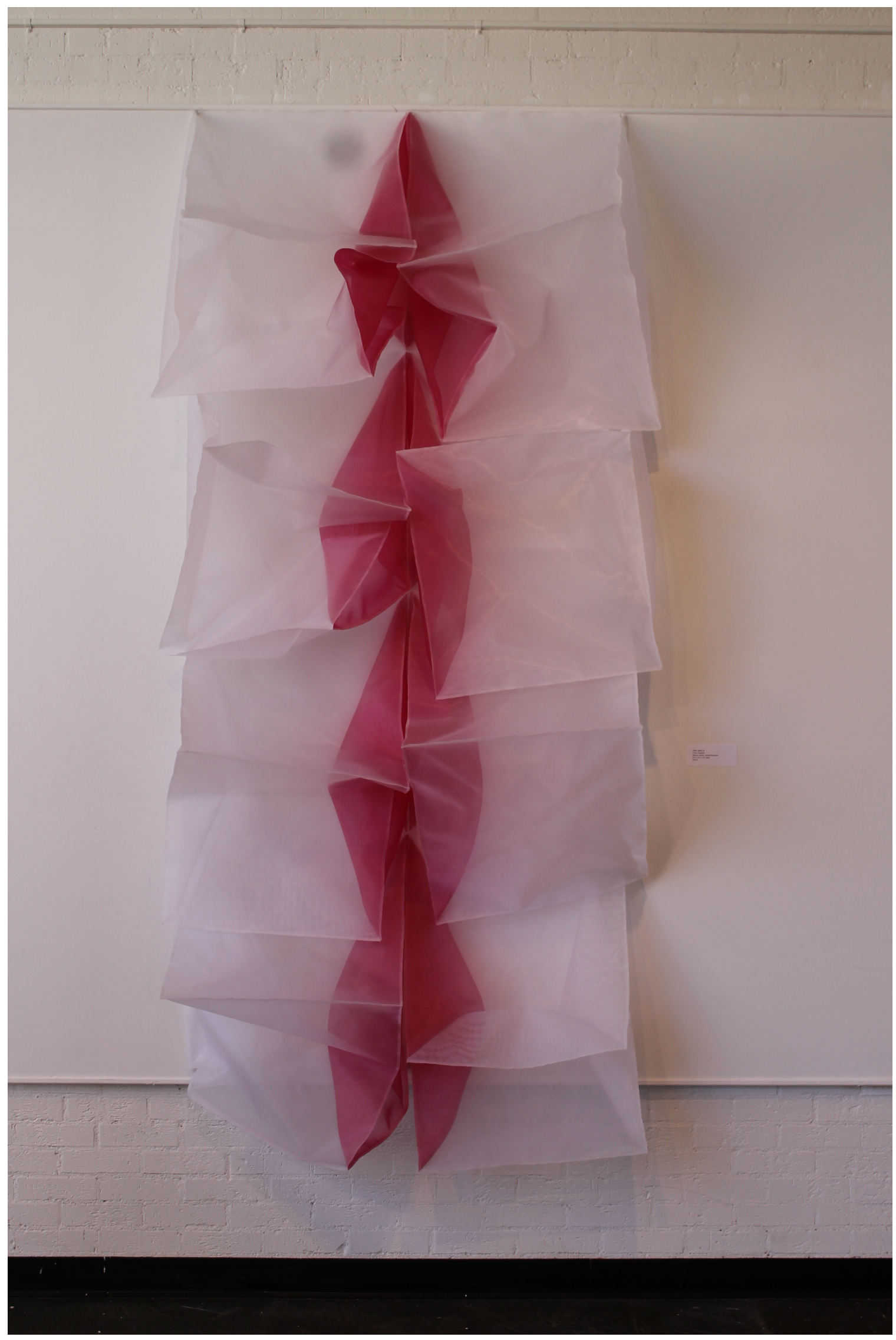




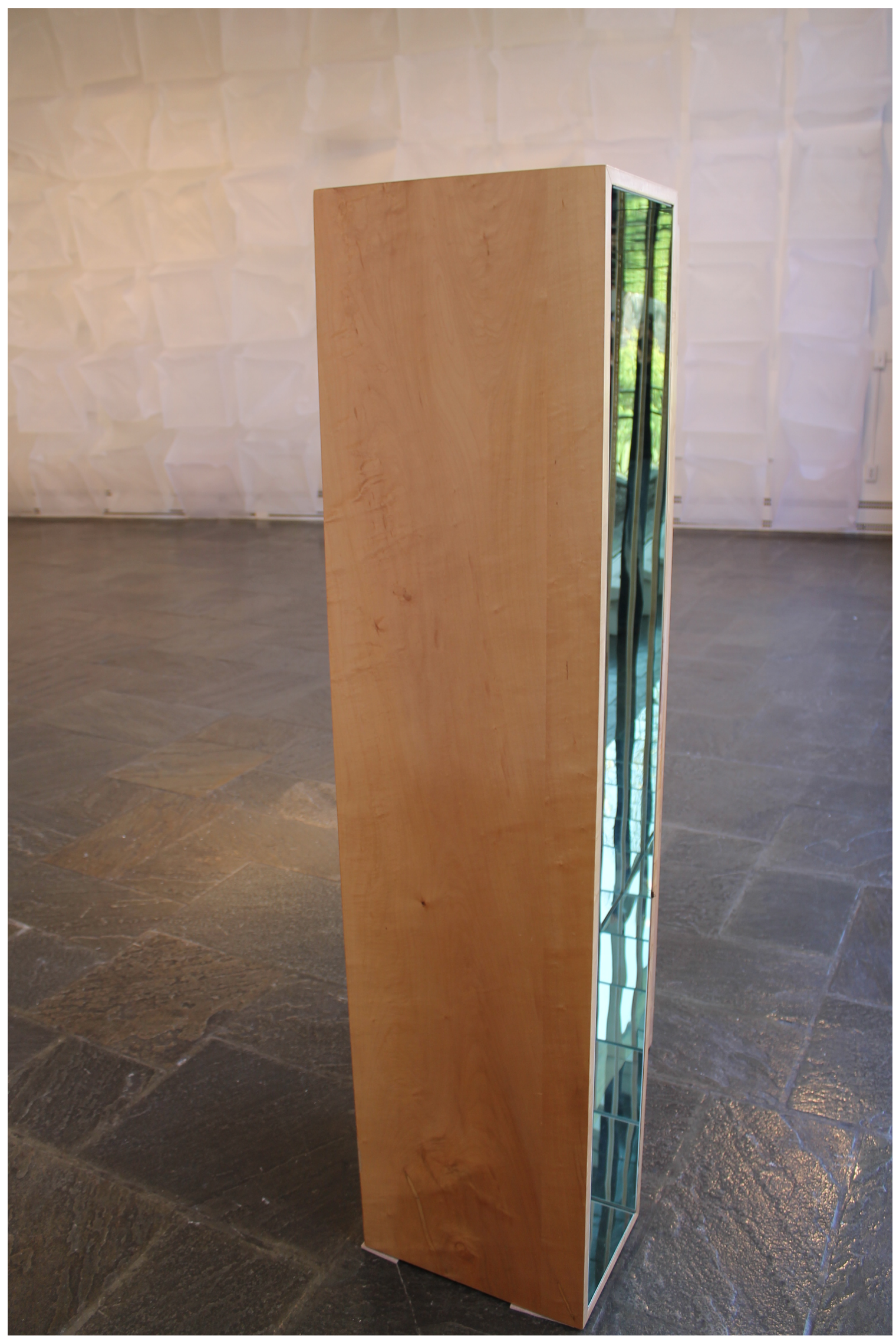

55 


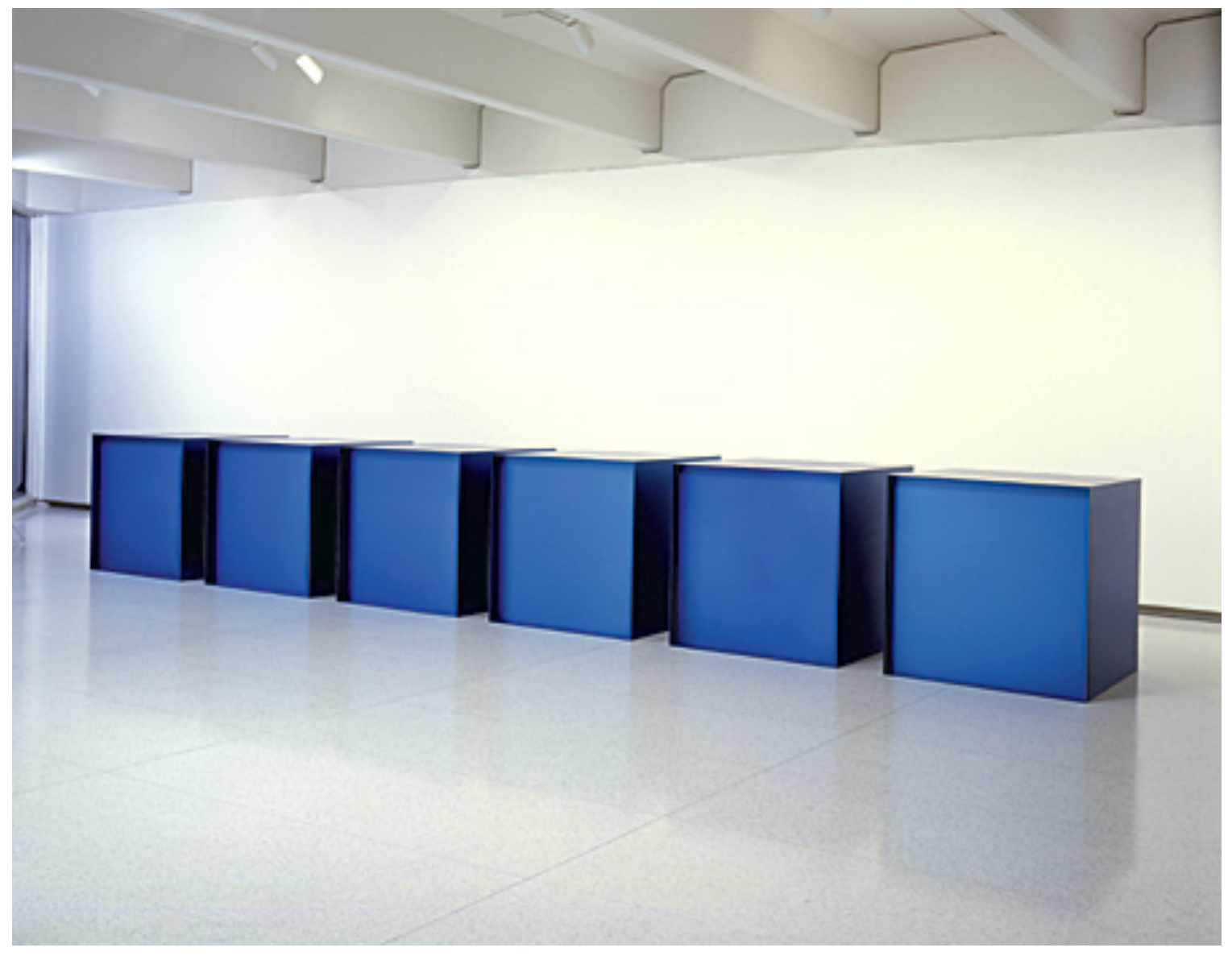

Figure 10: Donald Judd, untitled, 1971. Anodized aluminum. 48 x 48 x 48 in. each of 6 boxes, 48 x 108 x 48 in. overall installed. Collection Walker Art Center, Gift of the T. B. Walker Foundation, 1971. Image from: Walker Art Center website. 


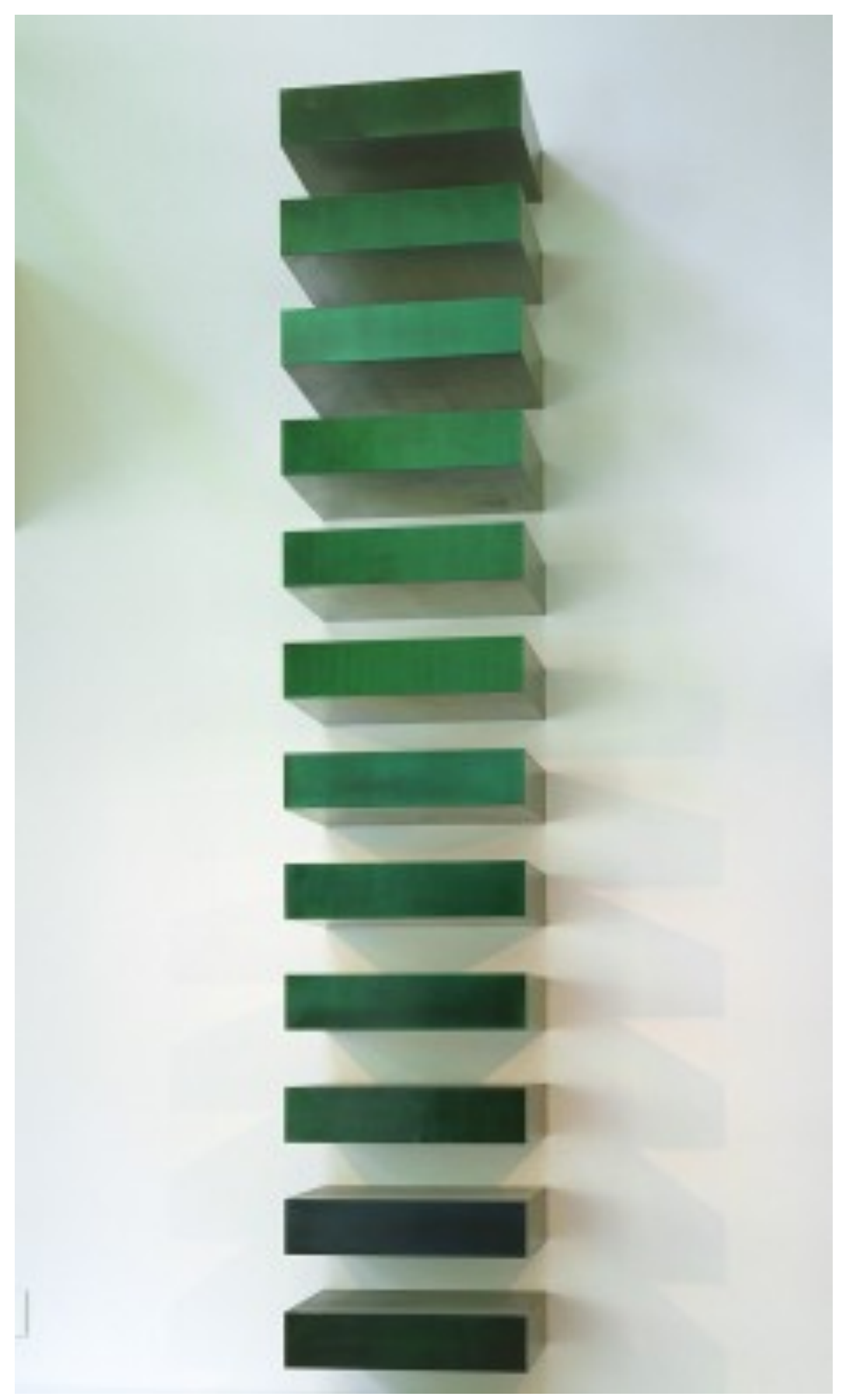

Figure 11: Donald Judd, Untitled (Stack), 1967. Lacquer on galvanized iron, Twelve units, each $9 \times 40 \times 31 "(22.8 \times 101.6$ × $78.7 \mathrm{~cm})$, installed vertically with $9 "(22.8 \mathrm{~cm})$ intervals. Image from: Museum of Modern Art website. 


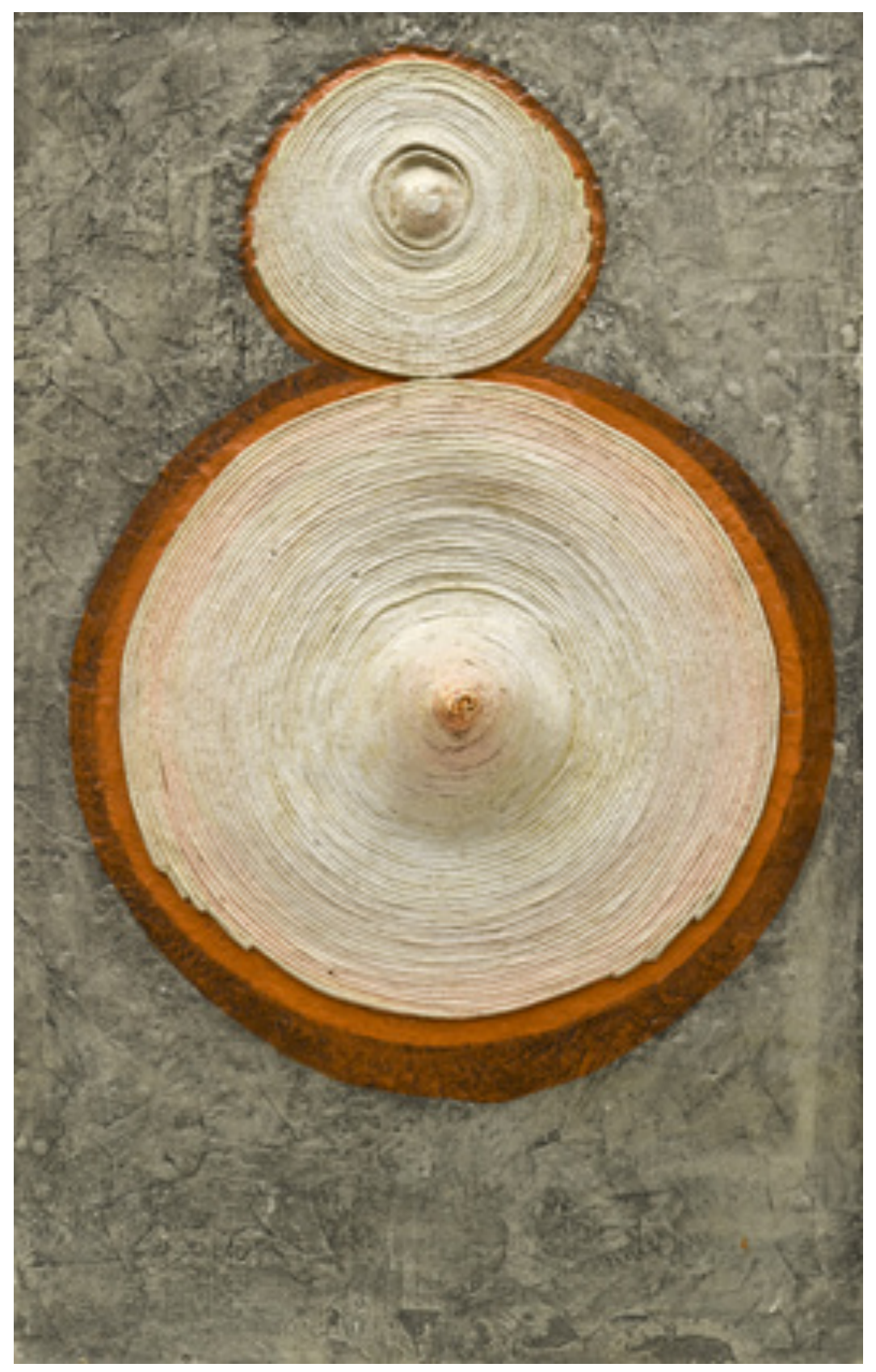

Figure 12: Eva Hesse, Ringaround Arosie, 1965. Pencil, acetone, varnish, enamel paint, ink, and cloth covered electrical wire on papier-mâché and masonite, 26 3/8 x 16 1/2 x 4 1/2" (67 x 41.9 x $11.4 \mathrm{~cm})$. Image from: Museum of Modern Art website. 


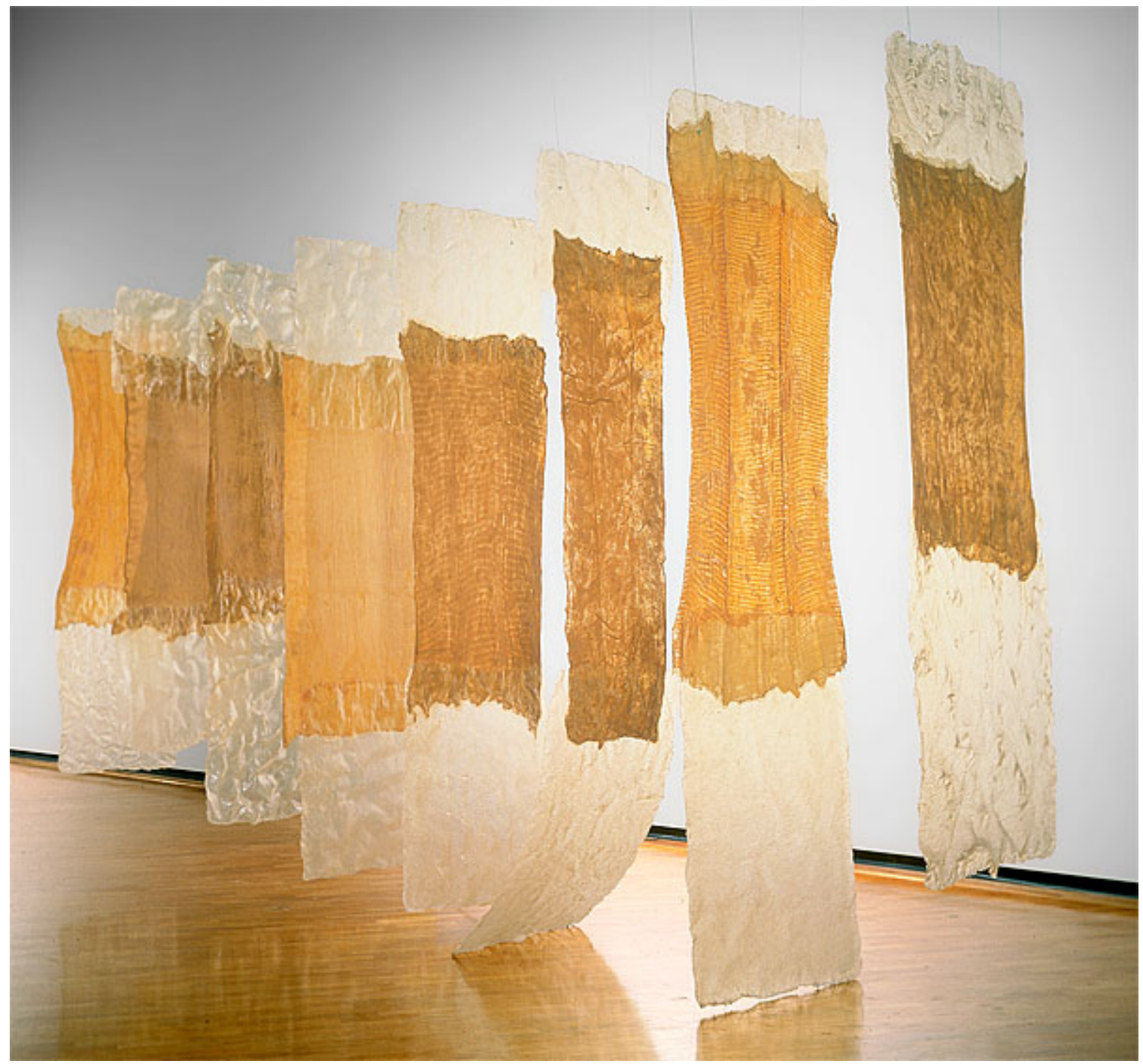

Figure 13: Eva Hesse, Contingent, 1969. Cheesecloth, latex, fiberglass. Overall 350.0 (h) x 630.0 (w) x 109.0 (d) cm. Purchased 1973. National Gallery of Australia, Canberra. Image from: National Gallery of Australia website. 


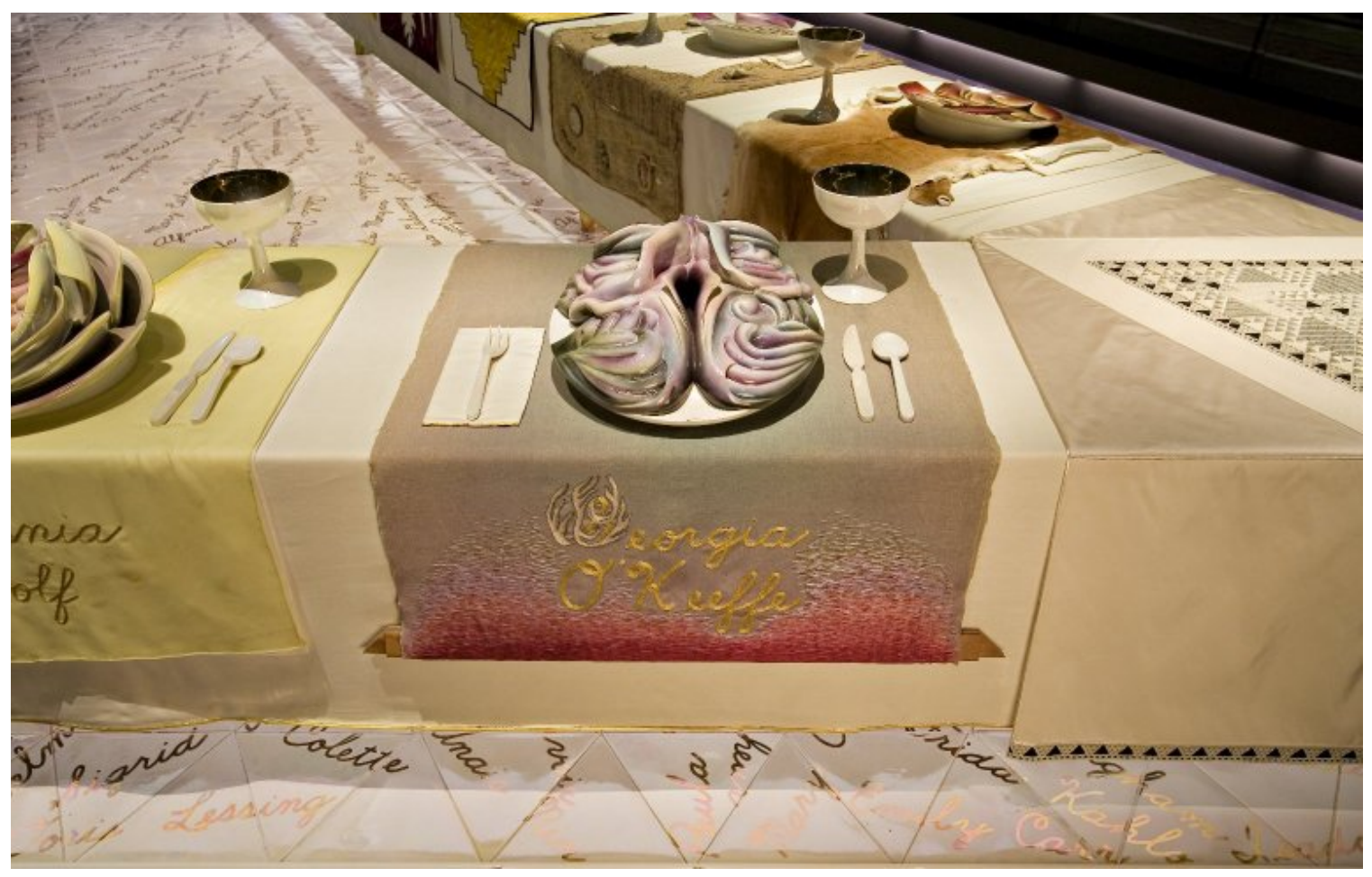

Figure 14: Judy Chicago, The Dinner Party (Georgia O'Keeffe runner), 1979. Belgian linen, cherry wood stretcher bars, cotton/linen base fabric, woven interface support material (horsehair, wool, and linen), cotton upholstery, steel carpet tacks, silk, synthetic gold cord, airbrushed acrylic paints, silk thread Plate: Porcelain with overglaze enamel (China paint). Runner: 52 1/4 x $321 / 4$ in. $(132.7$ x 81.9 cm) Plate: 14 1/2 x 14 x 4 3/4 in. (36.8 x 35.6 x $12.1 \mathrm{~cm})$. Image from: Brooklyn Museum website. 


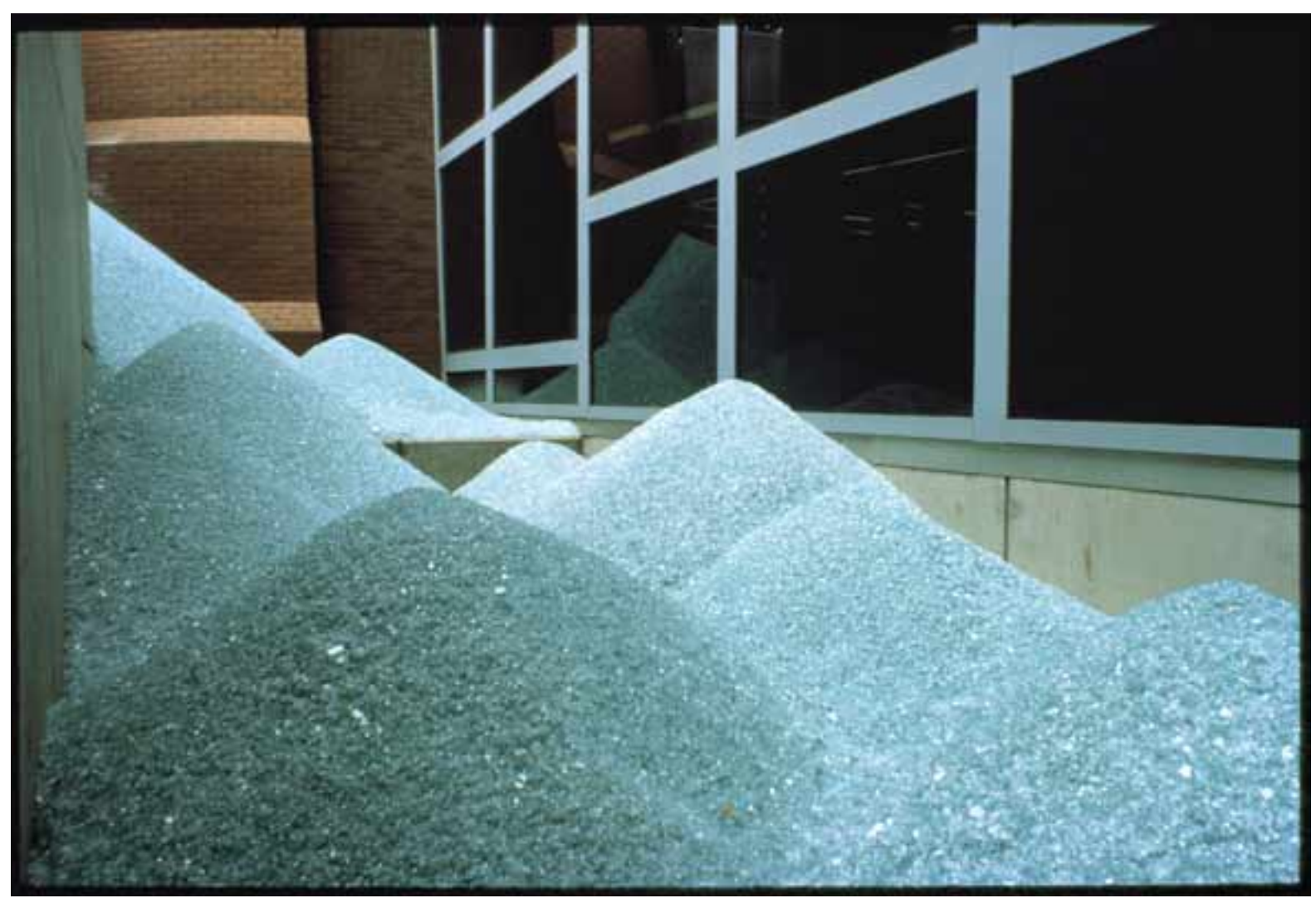

Figure 15: Maya Lin, Groundswell, 1993. Tempered safety glass. Permanent installation, commissioned by the Wexner Center for the Arts with support from the Wexner Center Foundation. Image from: https://prelectur.stanford.edu/lecturers/lin/ 


\section{APPENDIX D}

\section{Didactic Material}

Included below is the introduction panel, extended labels, and object labels installed alongside the art in Trace of a Body.

Introduction panel:

Trace of a Body is an exhibition of recent sculpture (from 2006-2014) made by Chris Radtke. The work on view is autobiographical. Radtke uses her body's volume configured in a variety of positions to create different forms. The artist selects the materials she utilizes to advance her expression of the inevitable impact of time, environment, and social interaction through the interplay of light, shadow and gravity.

Chris Radtke is a significant contemporary artist based in Louisville who has exhibited her art nationally. She is a co-founder of Zephyr Gallery in Louisville and is an active participant in the Louisville art scene as she readily shares her passion for creativity and collaboration.

\section{Extended label 1:}

Replication:

Radtke studies the field of genetics and heredity to better understand the idea of the copy and the replica in light of concepts of uniqueness and individuality. These 
qualities can be observed in Radtke's work, particularly Ghost (Wall) 96. This installation that has been configured in response to the gallery you stand in now, is comprised of 96 boxes made from nylon mesh. Each box is an exact duplicate of her body's measurements in a crouched position and yet each assumes a unique form as it responds to gravity.

Extended label 2:

Transparency/Distortion:

It is common for us to internalize our struggles and the negative impacts on our lives; we tend not to outwardly display the trepidations that plague our minds. These concerns are often masked as we present ourselves in a manner that may be authentic but incomplete. Radtke's work, particularly Deflated, illustrates how easily understandable a thing can be yet unexpected when closely considered.

\section{Extended label 3:}

\section{Reactions:}

In the work Curl Radtke demonstrates how quickly events occur and how they change us. For this work she shattered enough tempered glass to equal her body's volume. She recalls the act of shattering the glass as being a therapeutic venture; a simple tap on one area of the edge transformed entire sheets of glass into imperfect, varied particles. This recognition of imperfection is reinforced by the wood utilized in this work, as it was selected for its flaws and the trees' reaction the threats of its environment. 
Object labels:

Chris Radtke

Curl, 2008

Box elder, shattered tempered glass

$13 \% 3 / 4$ " x 20 " x $35 \frac{1}{2} / 2$ " each

Chris Radtke

Deflated, 2014

Tinted neon plastic

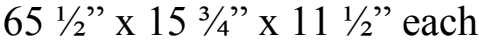

Chris Radtke

Ghost (wall) 96, 2010

Nylon mesh, monofilament

24 x 24 x 22 each

Chris Radtke

Pink (wall) 8, 2010

Nylon mesh, monofilament

$24 \times 24 \times 22$ each

Chris Radtke

Self 3, 2006

Flawed ash, mirror

$15 \frac{1 / 2}{2}$ x $15 \% 3 / 4$ " 9 1/2" each 


\section{CURRICULUM VITAE}

NAME: $\quad$ Bailey Marie Mazik

ADDRESS: 106 St. Francis Ct., Apt. 42

Louisville, KY 40205

DOB: $\quad$ Columbus, Ohio - February 19, 1990

EDUCATION

\& TRAINING: $\quad$ B.A., History of Art \& Strategic Communication The Ohio State University

2008-2013

Study Abroad, Berlin, Germany

06/2014-07/2014

Kentucky Institute for International Studies

AWARDS: Cressman Scholarship

Hite Art Institute, Department of Fine Arts, University of Louisville

2014-2015

Hite Scholarship

Hite Art Institute, Department of Fine Arts, University of Louisville

2013-2014

Dean's List

College of Arts and Sciences

The Ohio State University

2009-2013 (13/15 terms)

PROFESSIONAL SOCIETIES: American Alliance of Museums

Student Member

Joined 2013

PUBLICATIONS: The Untold Tale of Bob Lockhart: A Retrospective

Exhibition catalogue, Louisville, KY, 2014

Contributor to Lockhart Glossary 
PROFESSIONAL EXPERIENCE: Exhibitions \& Curatorial Intern Louisville Slugger Museum \& Factory Louisville, $\mathrm{KY}$ $08 / 2013-05 / 2015$

Curatorial Intern, American Art Columbus Museum of Art Columbus, $\mathrm{OH}$

$06 / 2012-03 / 2013$

Intern

Garth's Auctions, Inc.

Delaware, $\mathrm{OH}$

$06 / 2012-08 / 2012$

CURATED EXHIBITIONS: $\quad$ Trace of a Body

Hite Art Institute, University of Louisville 2015

A Century of Supporting the Troops Louisville Slugger Museum \& Factory 2014

Fantography:

Personal Moments in Professional Baseball Louisville Slugger Museum \& Factory 2013

ACTIVITIES: Aegis, Graduate Student Association University of Louisville 08/2013-05/2015 